\title{
Guinier-Preston Zone, Quasicrystal and Long-period Stacking Ordered Structure in Mg-based Alloys, A Review
}

\author{
Yongbo $X U^{1,2)^{\dagger}}$, Daokui $X U^{1)}$, Xiaohong $S H A O^{2)}$ and En-hou $H A N^{1)}$
}

1) State Key Laboratory for Corrosion and Protection, Institute of Metal Research, Chinese Academy of Sciences, Shenyang 110016, China

2) Shenyang National Laboratory for Materials Science, Shenyang 110016, China

[Manuscript received 18 January 2013, in revised form 28 March 2013]

(C) The Chinese Society for Metals and Springer-Verlag Berlin Heidelberg

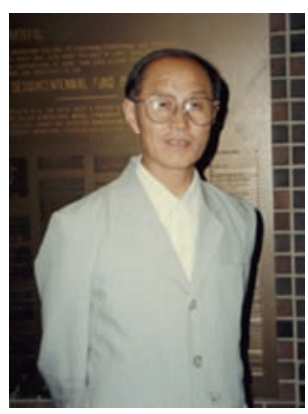

Yongbo XU, Professor of IMR, CAS, graduated from the Dept. of Physics of Jilin University in 1964. He visited McMaster University (1983-1984), Canada, and University of Virginia (1991-1993), USA, as a visiting scholar. The principle theme of his research is the relationship of mechanical behavior and the microstructures for advanced materials, mechanical and fracture behavior at the crack-tip of materials. He is the author or co-author of approximately 250 peer reviewed scientific papers, and co-edited three books in the related areas. He has been the recipient of several awards, including National Natural Science Award (second class) from State (1993), Natural Science Awards (second class) from Chinese Academy of Sciences (1989), Natural Science Award (second class) from Ministry of Education of China (2012), Science and Technology Award (second class) from China Aviation Society (2010), Science and Technology Awards (third class) from CAS (1990, 1992 and 1993), from Liaoning province (1993 and 2011). He received the understanding supervisors of the graduate students of CAS (1999 and 2008). He serves as several editorial board members of Int. J. Adv. Mater. and Acta Metall. Sin. (Engl. Lett.).

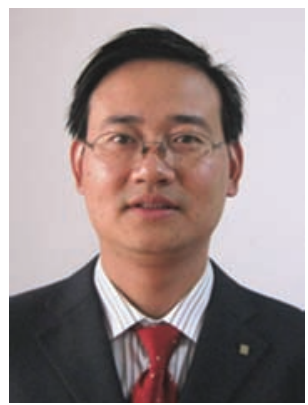

Daokui XU is an associate professor and "Young Merit Scholar" of Corrosion Center in the Institute of Metal Research (IMR), Chinese Academy of Sciences (CAS). He achieved Ph.D. degree from IMR, CAS in 2008. During which he obtained "Chinese Academy of Sciences-BHP Billiton" Scholarship award, "Shi Changxu" Scholarship award and "ZhuLiYueHua" Excellent Doctorate Student Scholarship of Chinese Academy of Sciences. He worked as a Research Fellow in ARC Center of Excellence, Design of Light Metals, Department of Materials Engineering, Monash University, Australia (2008.10-2011.10). He published more than 30 peer reviewed scientific papers, attended 10 invited lectures and holds 2 patents. His papers were cited more than 300 times. His research interests mainly include: (1) Fatigue behavior and fracture toughness of light metals, such as $\mathrm{Mg}$ and Al alloys; (2) Effects of alloying, heat treatment and thermomechanical processes on the microstructural evolution and mechanical improvement of light metals; (3) Corrosion, stress corrosion cracking and corrosion fatigue behavior of $\mathrm{Mg}$ and $\mathrm{Al}$ alloys; (4) Design of new lightweight alloys with a good balance of properties in terms of mechanical property and corrosion resistance.

Both the solid solution and precipitation are mainly strengthening mechanism for the magnesium-based alloys. A great number of alloying elements can be dissolved into the $\mathrm{Mg}$ matrix to form the solutes and precipitates. Moreover, the type of precipitates varies with different alloying elements and heat treatments, which makes it quite difficult to understand the formation mechanism of the precipitates in Mg-based alloys in depth. Thus, it is very hard to give a systematical regularity in precipitation process for the Mg-based alloys. This review

† Corresponding author. Prof.; Tel: +86 24 23971761; E-mail address: ybxu@imr.ac.cn (Yongbo XU) 
is mainly focused on the formation and microstructural evolution of the precipitates, as a hot topic for the past few years, including Guinier-Preston Zones, quasicrystals and long-period stacking ordered phases formed in a number of Mg-TM-RE alloy systems, where $\mathrm{TM}=\mathrm{Al}, \mathrm{Zn}, \mathrm{Zr}$ and $\mathrm{RE}=\mathrm{Y}, \mathrm{Gd}, \mathrm{Hd}, \mathrm{Ce}$ and $\mathrm{La}$.

\section{KEY WORDS: Guinier-Preston zone; Quasicrystal; Long-period stacking ordered struc- ture; Mg-based alloy}

\section{G.P. Zone (Guinier-Preston Zone)}

For a large class of commercial precipitationstrengthened alloys including $\mathrm{Al}-, \mathrm{Cu}-, \mathrm{Fe}-$, and $\mathrm{Mg}-$ alloys, the precipitation process mainly starts from formation of nanometer-sized coherent metastable precipitates known as Guinier-Preston (G.P.) zones which can inhibit dislocation glide leading to the increase of the flow stress. Generally, G.P. zones form at the very early stage of aging. As such, G.P. zones represent a key component of the precipitation processes. The discovery of G.P. zones in an age-hardened $\mathrm{Al}-\mathrm{Cu}$ alloy, was made by Guinier and Preston using X-ray Laue diffraction method in $1938^{[1,2]}$, and these G.P. zones are composed of Cu-rich layers parallel to [100] direction of the fcc Al-matrix. The segregation of $\mathrm{Cu}-$ atoms on $\{100\}$ planes of the Al-matrix is called G.P.I zones. However, the mono Cu-rich layers separated by three $\mathrm{Al}$ layers are G.P.-II zones, which can transform into $\theta$ and $\theta^{\prime}\left(\mathrm{CuAl}_{2}\right)$ phases ${ }^{[3-4]}$. Generally, the small space size of G.P. zones (on the order of one to several atom layers) makes it very difficult for the detection using the conventional electron microscopy.

Scientists and engineers have made lots of efforts to develop and improve the resolution capability of microscopy for the characterization of the precipitation process. In the long history of the development of characterization instruments, perhaps the greatest impact is the emergence of transmission electron microscope (TEM), which has become one of the primary tools for characterizing the nano- and micro- structures of materials, because of its very high resolution capability. For example, the commercial TEM is now routinely available with point resolution better than 2 angstroms $(\AA)(0.2 \mathrm{~nm})$. In particular, the advent of high-resolution transmission electron microscopy and three-dimensional atom probe (3DAP) as well as high-angle annular detector dark-field scanning transmission electron microscopy (HAADF-STEM) in materials sciences made it possible directly to resolve and detect geometric and structural features of G.P. zones in atomic scale.

Since the first discovery of G.P. zones, a great deal of investigations of G.P.-zone are mainly focused on Al-alloys. Fig. 1 shows HAADF micrographs of the G.P.-zones in $\mathrm{Al}-\mathrm{Cu}$ alloy, where the $\mathrm{Cu}$ atoms exhibit a bright contrast (Fig. 1(a)). Monatomic $\mathrm{Cu}$ layers as small as $2 \mathrm{~nm}$ in width can be clearly identified (Fig. 1(b)), where a G.P. zone is composed of two $\mathrm{Cu}$ layers indicated by an arrow in Fig. 1(b). It is also found that when the alloy is annealed at a higher temperature, these zones (G.P.-I) are known to transform into the G.P.-II zones, in which three Al layers are sandwiched by single $\mathrm{Cu}$ layers ${ }^{[5]}$.

Recently, the Mg-Zn based alloys are particularly interesting for the further development and application. A series of reports showed that a number of different kinds of coherent and semi-coherent precipitates were simultaneously present in the $\mathrm{Mg}-\mathrm{Zn}$ alloys aged at $70{ }^{\circ} \mathrm{C}$, including $[0001]_{\mathrm{Mg}}$ rods and laths, G.P. zone, G.P.-1 zones $\{0001\}$ plates and prismatic precipitates $\beta_{1}^{\prime}$ and $\beta_{2}^{\prime}$. The formation of the precipitates mainly depends on the aging temperature, and generally the precipitation sequence is as follows ${ }^{[6]}$ :

At $160{ }^{\circ} \mathrm{C}$ : SSSS $\rightarrow$ Zn clusters $\rightarrow$ G.P.-I zone + $\{0001\}_{\mathrm{Mg}}$ rods $+(0001)_{\mathrm{Mg}}$ G.P. zone $\rightarrow(0001)_{\mathrm{Mg}}$ G.P. zones $+(0001)_{\mathrm{Mg}}$ plates $+[0001]_{\mathrm{Mg}}$ rods $+[0001]_{\mathrm{Mg}}$ laths $\left(\beta_{2}^{\prime}\right)+[0001]_{\mathrm{Mg}}$ blocks $\left(\beta_{1}^{\prime}\right)+\beta_{2}^{\prime}$ laths.

At $98{ }^{\circ} \mathrm{C}: \mathrm{SSSS} \rightarrow \mathrm{Zn}$ clusters $\rightarrow$ prismatic precipitates $+(0001)_{\mathrm{Mg}}$ G.P. zones $+(0001)_{\mathrm{Mg}}$ plates + $[0001]_{\mathrm{Mg}}$ rods $+[0001]_{\mathrm{Mg}}$ laths.

At $70{ }^{\circ} \mathrm{C}:$ SSSS $\rightarrow$ Zn clusters $\rightarrow$ G.P.-I zones + prismatic precipitates $+(0001)_{\mathrm{Mg}}$ G.P. zones + $(0001)_{\mathrm{Mg}}$ plates $+[0001]_{\mathrm{Mg}}$ rods $+[0001]_{\mathrm{Mg}}$ laths.

At $22{ }^{\circ} \mathrm{C}: \mathrm{SSSS} \rightarrow$ Zn clusters $\rightarrow$ G.P.-I zones + prismatic precipitates.

After the addition of $\mathrm{Ca}$ to the $\mathrm{Mg}-\mathrm{Zn}$ alloys, the ageing hardening response of the alloys can be enhanced by forming finer precipitates of $\beta_{1}^{\prime}$ and $\beta_{2}^{\prime[7]}$, as well as the formation of monolayer G.P. zones ${ }^{[8]}$. However, the addition of $\mathrm{Cu}$, and even a trace amount of $\mathrm{Cu}$ to the $\mathrm{Mg}$ - $\mathrm{Zn}$ alloys can enhance the nucleation of the precipitates and accelerate the kinetics of precipitation, in particular during natural aging. This is believed to be a result of the enhanced favorable interaction between $\mathrm{Cu}, \mathrm{Zn}$ and vacancies. The strengthening is mainly ascribed to the formation of a very high density of the coherent disc-shaped G.P.-I.

Fig. 2 shows the TEM image (Fig. 2(a)) and HREM image (Fig. 2(b)) obtained from the $\mathrm{Mg}_{97.5} \mathrm{Gd}_{1.5} \mathrm{Zn}_{1}$ alloy annealed at $200^{\circ} \mathrm{C}$ for $100 \mathrm{~h}$ taken with the incident beam perpendicular to $c$-axis of the Mg-matrix. The line contrasts perpendicular to the $c$-axis in Fig. 2(a) are recognized to be the planar G.P. zones being parallel to close-packed planes of the Mg-matrix. Most of the G.P. zones with 50$100 \mathrm{~nm}$ lengths are isolated and independently distributed, and some of them are double G.P. zones 

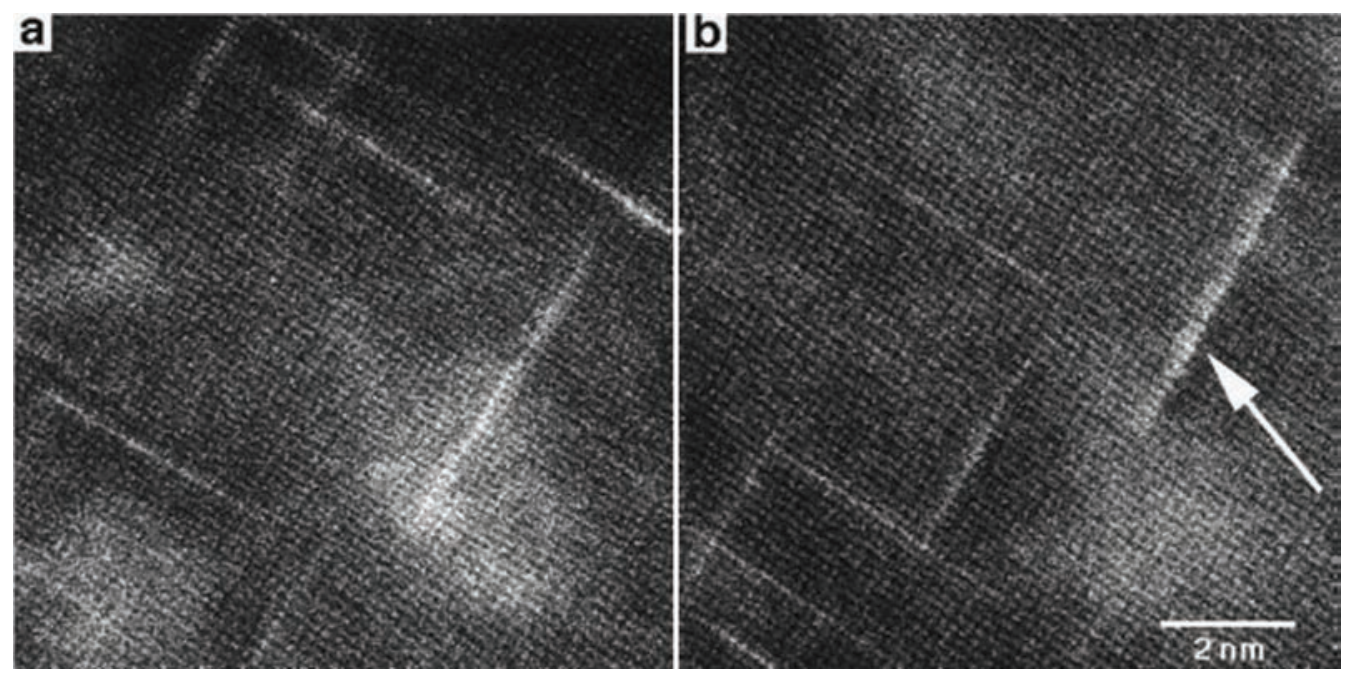

Fig. 1 HAADF micrographs of the G.P. zones in Al-Cu alloy: (a) intercalated monatomic Cu layers several nanometres in width; (b) a two $\mathrm{Cu}$ layers thick G.P.-zone ${ }^{[5]}$

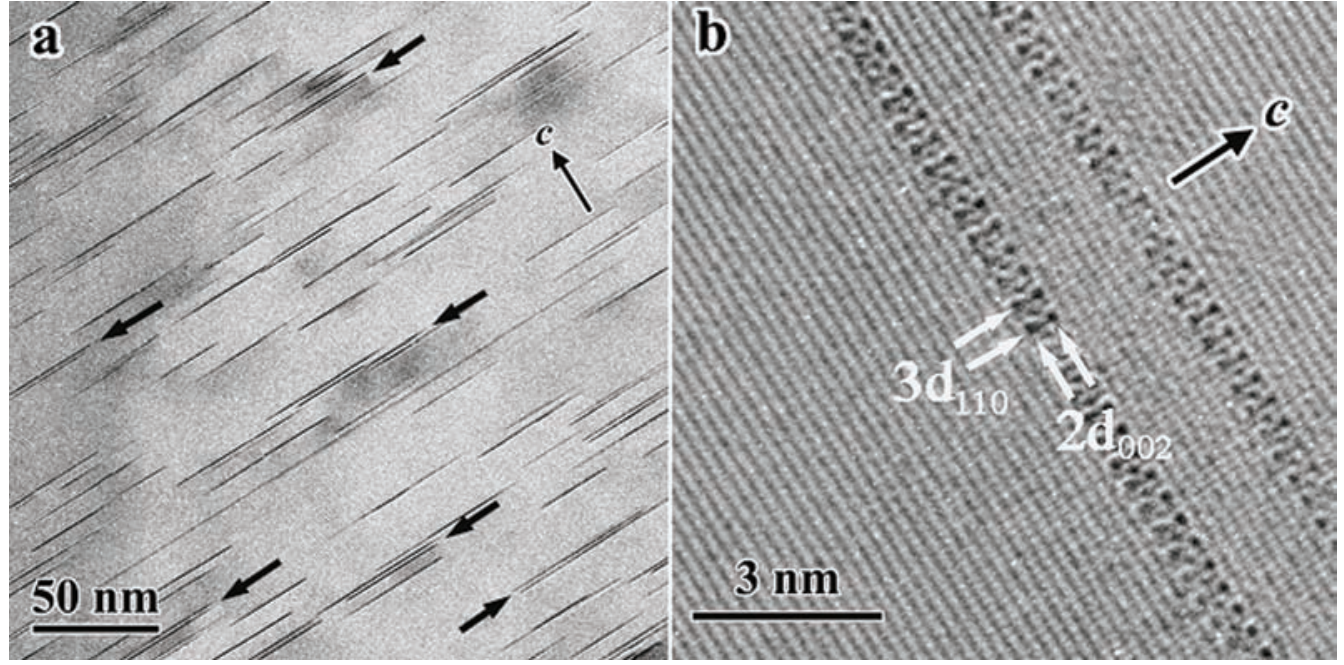

Fig. 2 TEM (a) and HRTEM (b) images of $\mathrm{Mg}_{97.5} \mathrm{Gd}_{1.5} \mathrm{Zn}_{1}$ cast alloy taken with the incident beam perpendicular to the $c$-axis (White arrows in Fig. 2(b) indicate double G.P. zones with a definite interval) ${ }^{[9]}$

with an interval of about $3 c=1.5 \mathrm{~nm}$ ( $c$ is a lattice constant of the hcp Mg structure) as indicated by arrows in Fig. 2(a). The HREM image shows the G.P. zones (Fig. 2(b)), where the dark dots with an interval of a $2 d_{002}$ spacing of the hcp $\mathrm{Mg}$ lattice are periodically arranged with an interval of a $3 d_{110}$ spacing. The bright dots shown in Fig. 2(b) represent Gd and/or $\mathrm{Zn}$ atoms projected along the $1 \overline{1} 0_{\mathrm{M}}$ direction ${ }^{[9,10]}$.

Fig. 3 shows electron diffraction patterns taken from $\mathrm{Mg}_{97} \mathrm{Gd}_{2} \mathrm{Zn}_{19}$ (Fig. 3(a) and Fig. 3(b)) and $\mathrm{Mg}_{97.5} \mathrm{Gd}_{1.5} \mathrm{Zn}_{1}$ (Fig. 3(c) and Fig. 3(d)) as-cast alloys. Analysis reveals that the weak spots in Fig. 3(a) and Fig. 3(b) from both $\beta^{\prime}$ and G.P. zones, and the extra sports at the positions of $1 / 3,1 / 3$ and 0 are shown in Fig. 3(c), and streak reflections shown in Fig. 3(d) are from G.P. zone.

3DAP technique can effectively detect distribution of elements in G.P. zone at atomic level ${ }^{[8,11]}$. Fig. 4(a) is a bright field image of G.P. zone creating in a MgRE-Zn-Zr casting alloy. HREM reveals that most of G.P. zones form on a single (0001) a plane of the $\mathrm{Mg}$ matrix (Fig. 4(b)). It is seen clearly that a distinguishable contrast variation (marked by arrows) may be caused by the segregation of the rare-earth elements in a single atomic layer of the basal plane due to the strain extended at both sides of the G.P. zone.

Fig. 5 shows the element distributions of $\mathrm{Nd}, \mathrm{Ce}$, $\mathrm{Zn}$ and $\mathrm{Zr}$ in G.P. zones obtained by 3DAP. It can be seen that there are three types of G.P. zones marked by arrows and two of them are quite similar and separated by only three or four basal planes of the $\mathrm{Mg}$ matrix. Moreover, these two G.P. zones are enriched by Nd, Ce and Zn, but no segregated by Zr. These results can further support the occurrence of G.P. zone in these kinds of Mg-RE alloys ${ }^{[10]}$.

From these observations, a structural model for 


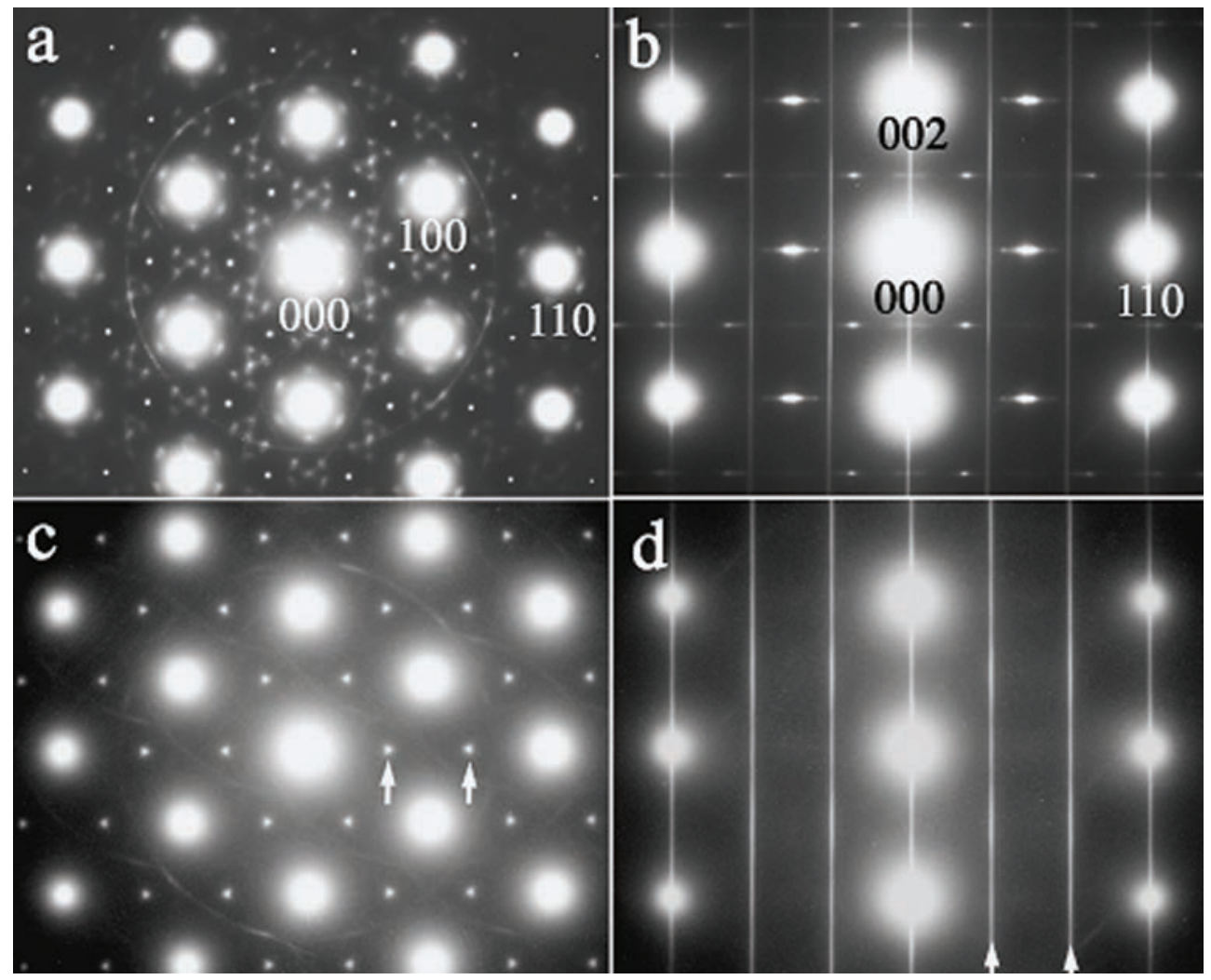

Fig. 3 Electron diffraction patterns of $\mathrm{Mg}_{97} \mathrm{Gd}_{2} \mathrm{Zn}_{1}$ (a, b) and $\mathrm{Mg}_{97: 5} \mathrm{Gd}_{1: 5} \mathrm{Zn}_{1}$ (c, d) cast alloys taken with the incident beam parallel to [001] $(\mathrm{a}, \mathrm{c})$ and $[1 \overline{1} 0](\mathrm{b}, \mathrm{d})$ directions of the HCP Mg-matrix ${ }^{[9]}$

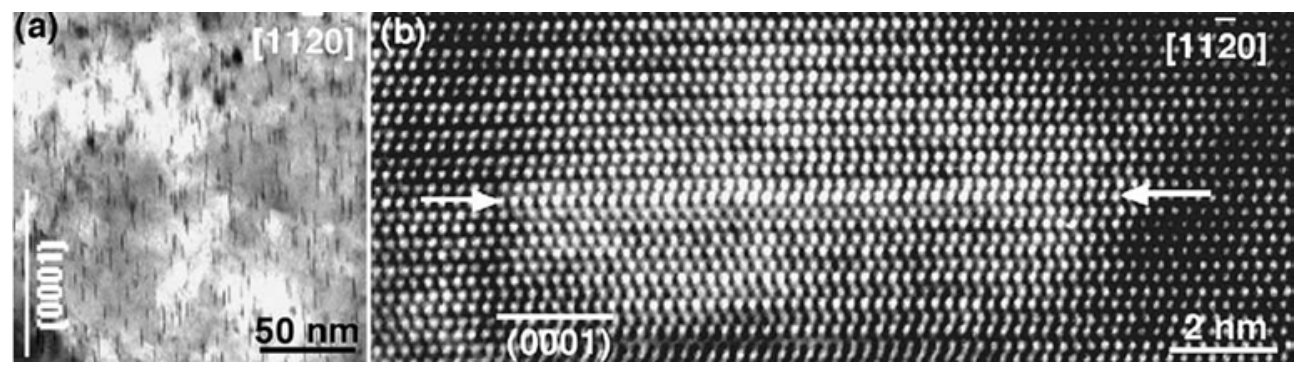

Fig. 4 Bright-field (a) and HRTEM (b) images of G.P. zone in Mg-RE-Zn-Zr cast alloy ${ }^{[11]}$
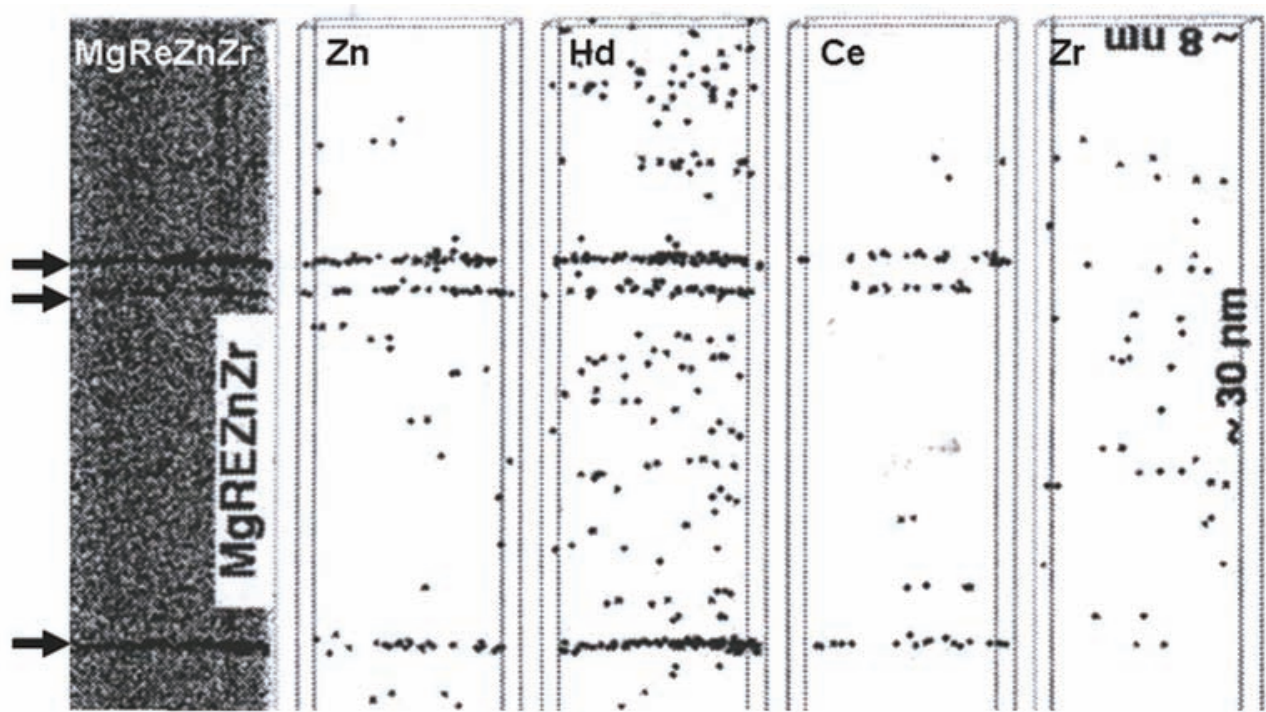

Fig. 5 Element mappings of $\mathrm{Nd}, \mathrm{Ce}, \mathrm{Zn}$ and $\mathrm{Zr}$ obtained by 3DAP (Each black dot represents one atom) ${ }^{[11]}$ 
(a)

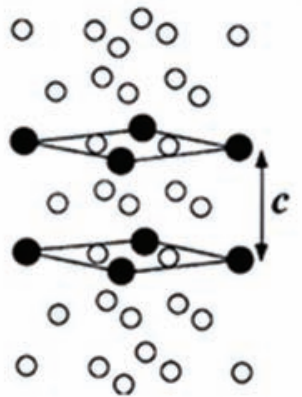

(c)

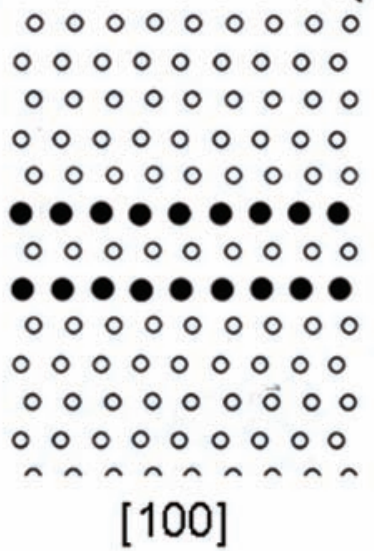

(b)

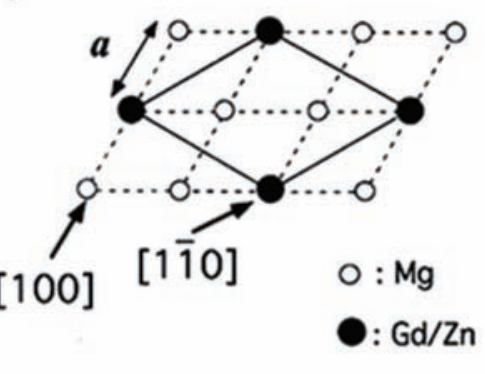

(d)

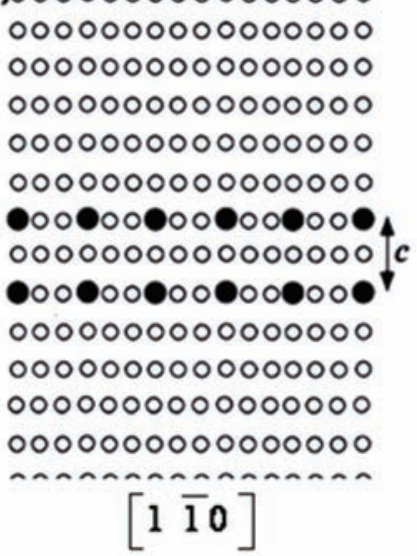

Fig. 6 A structural model for G.P. zone of the $\mathrm{Mg}_{97} \mathrm{Gd}_{2} \mathrm{Zn}_{1}$ cast alloy (a, b) and projected atomic arrangements along $[100](\mathrm{c})$ and $[1 \overline{1} 0](\mathrm{d})$ directions ${ }^{[10,12]}$

G.P. zones in the $\mathrm{Mg}_{97} \mathrm{Gd}_{2} \mathrm{Zn}_{1}$ alloy was constructed as shown in Fig. 6, where $\mathrm{Gd}$ and $\mathrm{Zn}$ atoms are located in two close-packed planes of the $\mathrm{Mg}$ matrix (Fig. 6(a)), and occupy the ordered positions (Fig. 6(b)). The atomic arrangements projected along the [110] and [1 10$]$ directions are drawn in Fig. 6(c) and Fig. 6(d) respectively, where a pair of Gd-Zn atoms distanced apart by $c$ is periodically and horizontally arranged with an interval of either $d_{010}=0.28 \mathrm{~nm}$ for the [100] view or $3 d_{110}=0.28 \mathrm{~nm}$ for the $[1 \overline{1} 0]$ view. This geometrical model can be further confirmed by the atomic-scale HAADF-STEM observation to the G.P. zones in a $\mathrm{Mg}_{97.5} \mathrm{Gd}_{1.5} \mathrm{Zn}_{1}$ as-cast alloy after annealing at $200{ }^{\circ} \mathrm{C}$ for $100 \mathrm{~h}^{[10]}$.

\section{Quasicrystal}

One observation of the quasicrystals in a rapid solidification of Al-rich Al-Mn alloys by melt spinning at 1984 was made by Schechtman, who is the 2011 recipient of the chemistry Nobel prize for his discovery of quasi-crystals. He stated in his report that the existence of a metallic solid which diffracts electrons like a single crystal but has point group symmetry $m \overline{35}$ (icosahedral), which is inconsistent with lattice translations. Selected-area electron diffraction patterns clearly display the six fivefold, ten threefold, and fifteen twofold axes characteristic as shown in Fig. 7. They refer to this kind of phase as the icosahedral phase with no translational order and with long-range orientational order ${ }^{[13]}$.

At the same time, Chinese scientist, Kuo and his colleagues, found quasicrystals with fivefold rotational symmetry in the nano-domains in $\sigma$ and Laves phases in Fe- and Ni-matrix alloys (1984) and soon after, they again found quasicrystal in $\mathrm{Ti}-\mathrm{V}-\mathrm{Ni}$ alloy in 1985 , as shown in Fig. $7(b)^{[14-17]}$. It is well known that the fivefold symmetry is forbidden in traditional crystallography and is inconsistent with lattice translations. Therefore, this kind of discovery created a great shock and impact in solid state physics, chemistry, as well as materials sciences and the related fields and since then an argument took place around the formation and existence of quasicrystals. Pauling argued in his series papers that so-called icosahedral and decagonal quasicrystals as mentioned in Schechtman's paper are, in fact, twins of an 820-atom cubic crystal and he considered that any single crystal with 5 -fold axes could not give reasonably sharp diffraction patterns, resembling those given by crystals ${ }^{[18-20]}$. Soon after that, however, evidences from a series of studies by Xray and TEM confirmed further the existence of the fivefold rotational symmetry quasicrystals with longrange orientational order, but with icosahedral pointgroup symmetry ${ }^{[21-24]}$ and after then, quasicrystals with 8-, 10-, and 12-fold symmetry have also been found successively ${ }^{[25-36]}$. 

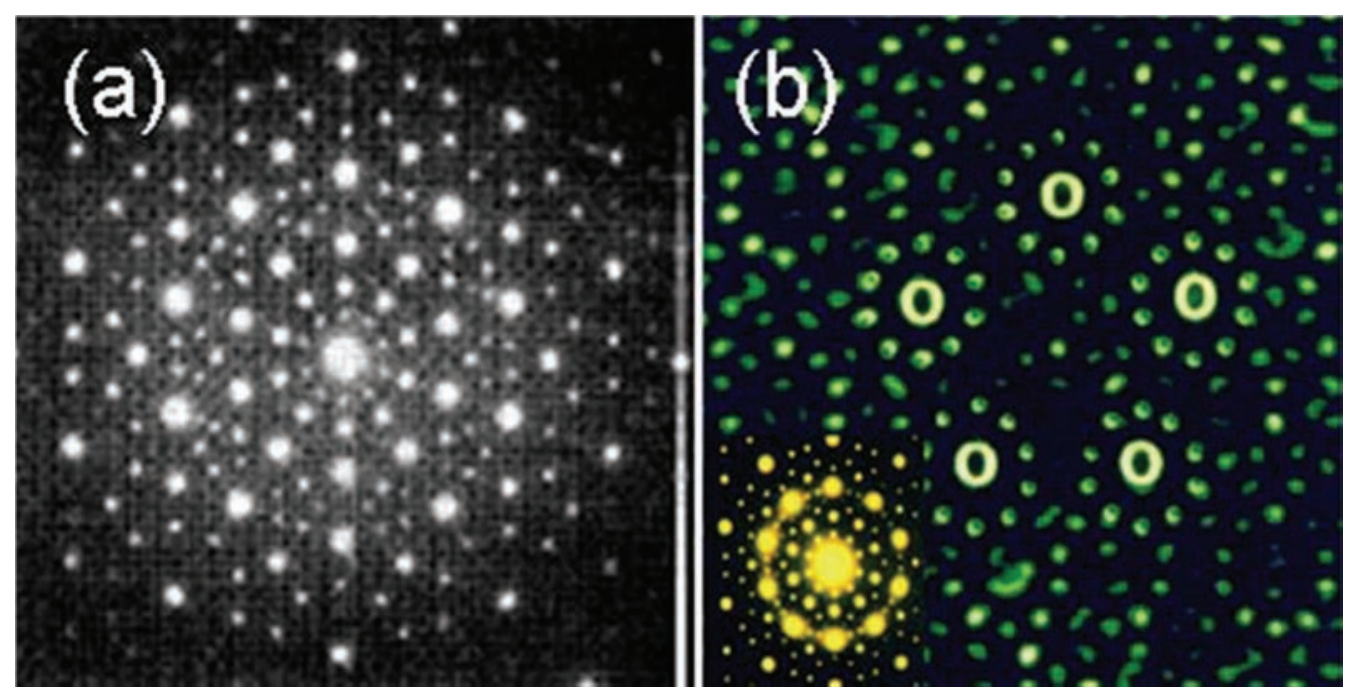

Fig. 7 Selected-area electron diffraction patterns from the quasicryatls in a rapid solidification of Al-4 at.\%Mn by melt spinning $(\mathrm{a})^{[13]}$ and in Ti-V-Ni alloys $(\mathrm{b})^{[14]}$

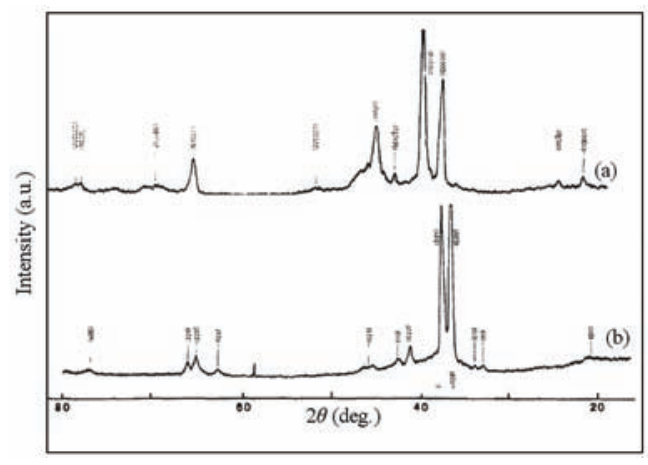

Fig. 8 X-ray diffraction patterns $\left(\mathrm{Cu} K_{\alpha}\right)$ from rapidly quenched $\mathrm{Mg}_{32}(\mathrm{Al}, \mathrm{Zn})_{49}(\mathrm{a})$ and $\mathrm{Mg}_{2} \mathrm{Al}_{3}(\mathrm{~b})^{[24]}$

The studies of the quasidracrystals in magnesium alloys mainly focused on the systems of $\mathrm{Mg}-\mathrm{Al}-X$ $(X=\mathrm{Zn}$, and $\mathrm{Cu} . \ldots$.$) and \mathrm{Mg}-\mathrm{Zn}-\mathrm{RE}(\mathrm{Re}=\mathrm{Y}, \mathrm{Gd}$, and $\mathrm{Nd}, \ldots \ldots$... For the former, the quasidracrystals were usually observed in Mg-alloys produced by rapid solidification $^{[37-42]}$.

The earlier observations of quasicrystals in magnesium alloys was reported by Rajasekharan et al..$^{[24]}$ in rapidly quenched $\operatorname{Mg}_{32}(\mathrm{Al}, \mathrm{Zn})_{49}$ (Fig. 8(a)) and $\mathrm{Mg}_{2} \mathrm{Al}_{3}$ (Fig. 8(b)) and by Mukhopadhyay et al. ${ }^{[28]}$ in $\mathrm{Mg}_{32}(\mathrm{Al}, \mathrm{Zn}, \mathrm{Cu})_{49}$ alloy, showing the occurrence of quasicrystals in these alloys. These results are firmly confirmed by the TEM observation shown in Fig. 9, where is the selected area diffraction pattern with 5fold symmetry from rapidly solidified $\mathrm{Mg}_{32}(\mathrm{Al}, \mathrm{Zn})_{49}$.

Although the quasicrystals mentioned above were mainly produced by non-equilibrium technique, these kinds of icosahedral quasicrystals have also been reported in many conventionally processed $\mathrm{Mg}$ alloys $^{[43-59]}$.

The first observation of the quasicrystal phase in an as-cast Mg-Zn-RE, where RE represents $\mathrm{Y}$ or mix-

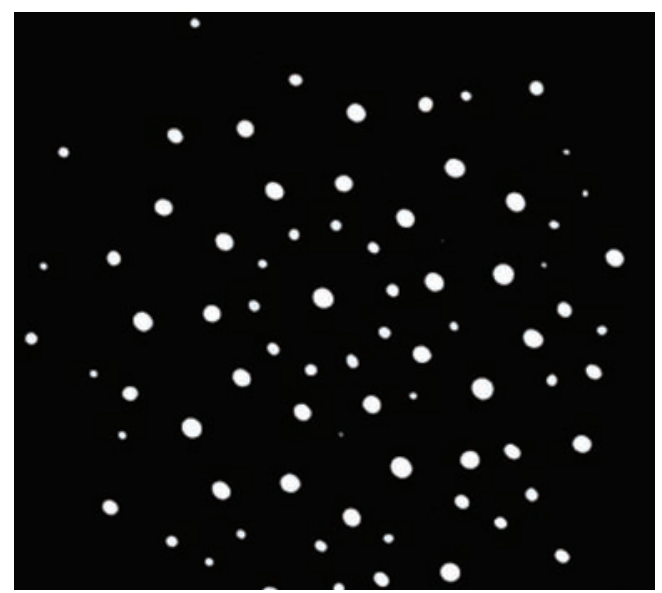

Fig. 9 Selected area diffraction pattern with 5-fold symmetry from rapidly solidified $\mathrm{Mg}_{32}(\mathrm{Al}, \mathrm{Zn})_{49}^{[24]}$

ture of rare-earths elements of Y, Nd, Gd, Dy and La etc. was made by Luo et al.(1993) ${ }^{[50]}$. They found three kinds of crystals, $\mathrm{W}, \mathrm{W}^{\prime}$ phases (having the same structures (fcc) and the space group $(F m 3 m)$ ), $\mathrm{MgZn}_{2}$-type Laves phase, coexisting with the quasicrystals. Fig. 10 shows the typical SEDPs taken from the quasicrystal phase in a Mg-Zn-Y cast alloy, revealing a distinct characteristic icosahedral quasicrystal with 5-, 3- and 2-fold symmetry axes ${ }^{[50]}$.

A series of subsequent researches further verified the existence of the icosahedral quasicrystal in the same rare-earth containing $\mathrm{Mg}$ alloy systems ${ }^{[1-59]}$. Yi et al. ${ }^{[60]}$ reported that the icosahedral quasicrystal (I-phase) can be formed by a peritectic reaction. As the first step, $(\mathrm{Zn}, \mathrm{Mg})_{5} \mathrm{Y}$ is crystallized in the liquid: $L \rightarrow(\mathrm{Zn}, \mathrm{Mg})_{5} \mathrm{Y}$, and then $L+(\mathrm{Zn}, \mathrm{Mg})_{5} \mathrm{Y} \rightarrow \mathrm{I}$-phase as shown in Fig. 11, indicating the formation process of the I-phase in Mg-Zn-Y as-cast alloy ${ }^{[60]}$.

Fig. 12 shows that the icosahedral quasicrystal 

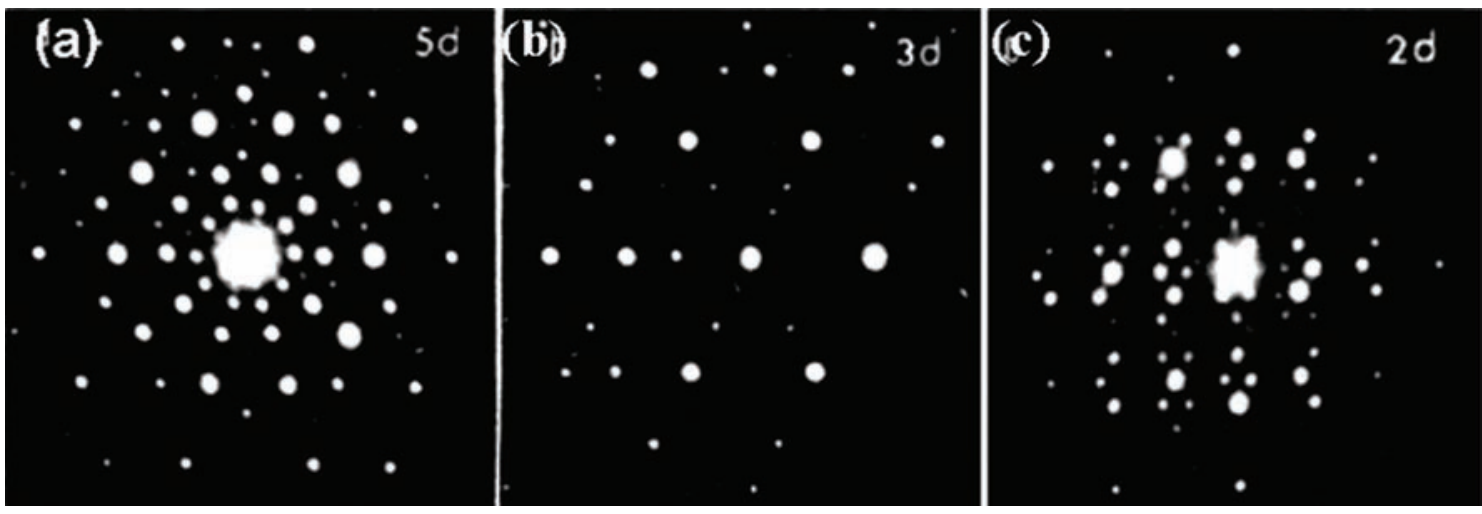

Fig. 10 SEDPs from quasicrystals in a Mg-Zn-RE cast alloy showing 5-fold (a), 2-fold (b) and 3-fold (c) symmetries $^{[50]}$

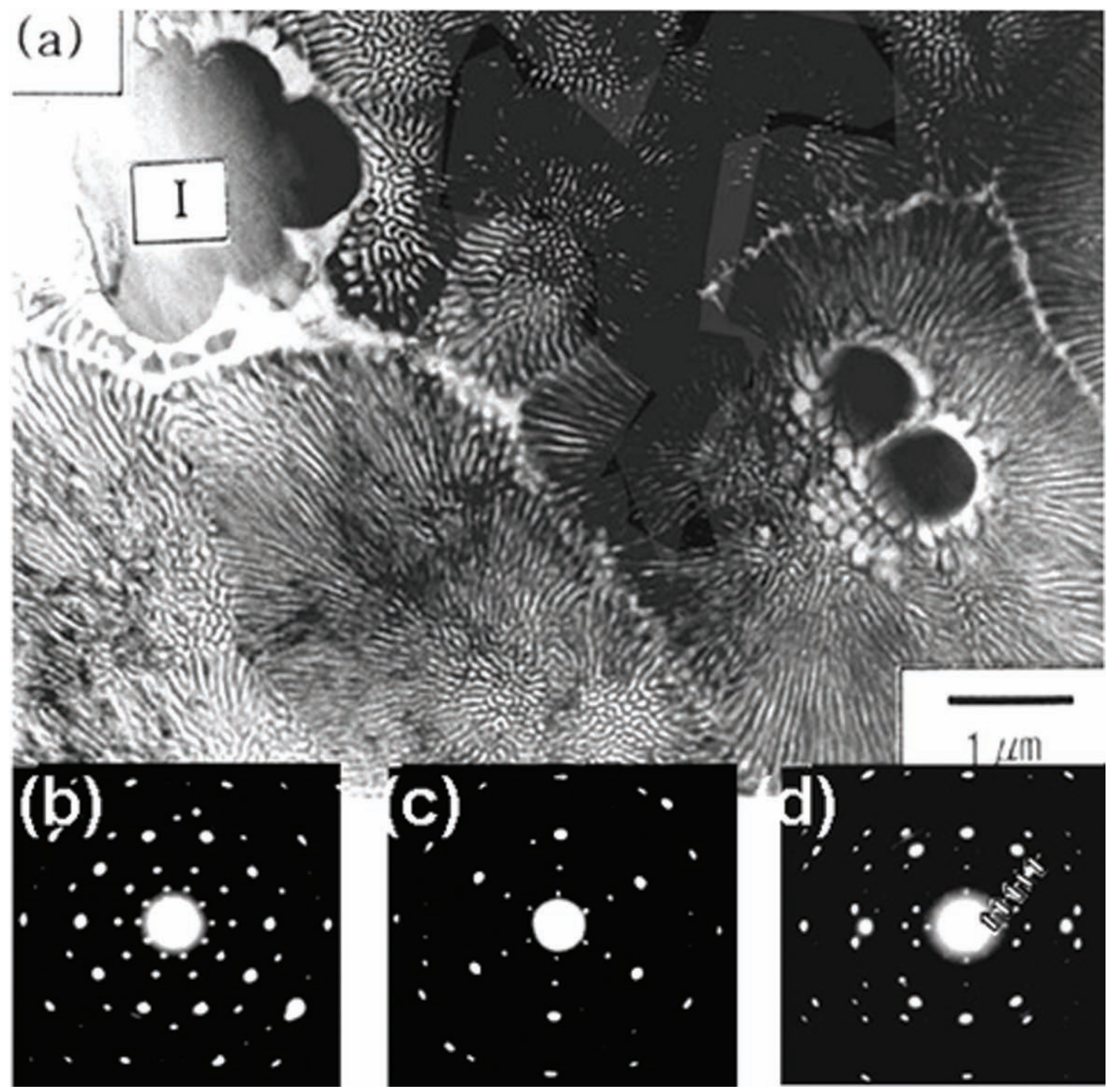

Fig. 11 TEM image taken from as-cast $\mathrm{Mg}_{71.8} \mathrm{Zn}_{25.2} \mathrm{Y}_{3}(\mathrm{a})$, and SAEDP obtained from icosahedral phase (marked by I) of the lamellar eutectic structure (a) and corresponding to 5-fold (b), 3-fold (c) and 2-fold (d) symmetry axes ${ }^{[60]}$ 


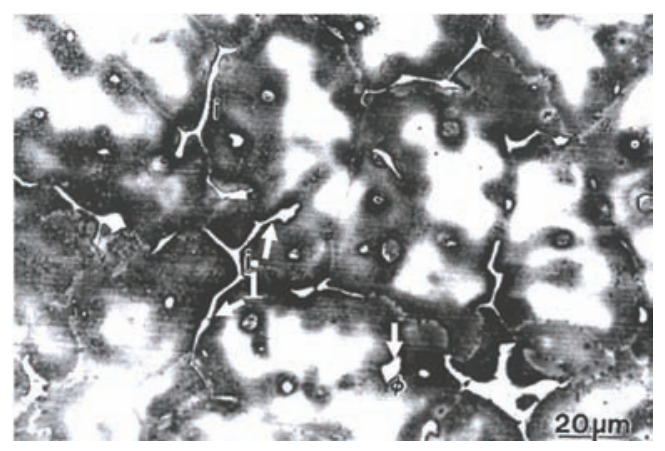

Fig. 12 The icosahedral quasicrystal phase (marked by i) and a globular phase (marked by $\Phi$ ) in a $\mathrm{Mg}-\mathrm{Zn}$ Al cast alloy ${ }^{[43]}$

(marked by i) were also found in a $\mathrm{Mg}-\mathrm{Zn}-\mathrm{Al}$ as-cast alloy. Micro-diffraction patterns taken from the icosahedral quasicrystal phase show the typical 5-, 3- and 2-fold symmetry zones (Fig. 13).

Analysis confirms that this dendritic phase has primitive icosahedral structure with an average composition of $\mathrm{Mg}_{9 \pm 2} \mathrm{Zn}_{4 \pm 1} \mathrm{Al}_{3 \pm 1}$, a space group of $m \overline{35}$ and a quasilattice parameter of $0.515 \mathrm{~nm}$, which is close to those of icosahedral phases obtained in rapidly solidified alloys by Rajasekharan et al. ${ }^{[24]}$ and Mukhopadhyay et al. ${ }^{[28]}$, but smaller than that of $\mathrm{Mg}_{32} \mathrm{Zn}$-type icosahedral qnasicrystals Al-Mg-Zn alloy formed by solid-state reaction and rapid solidification .

Further work revealed that this kind of icosahedral quasicrystal is a metastable under prolonged holding at $325^{\circ} \mathrm{C}$, and it will transform into the equilibrium phase $\phi\left(\mathrm{Mg}_{21}(\mathrm{Al}, \mathrm{Zn})_{17}\right.$ with space group of $\mathrm{Pbcm}{ }^{[44]}$.

More recently, Rosalie et al. ${ }^{[48]}$ reported that icosahedral clusters can form in hexagonal $\mathrm{MgZn}_{2}$ and monoclinic $\mathrm{Mg}_{4} \mathrm{Zn}_{7}$ phases in a $\mathrm{Mg}-\mathrm{Zn}-\mathrm{Y}$ as-cast alloy subjected to be compressively deformed. Both phases are structurally related to the quasicrystals which form in the Mg-Zn-Y alloy. Fast Fourier Transforms (FFTs) (inserts) show existence of both $\mathrm{MgZn}_{2}$ and $\mathrm{Mg}_{4} \mathrm{Zn}_{7}$ on the twin boundary as shown in Fig. 14 .

According to these observations above, the constructed structural models of two phases of $\mathrm{Mg}_{4} \mathrm{Zn}_{7}$ and $\mathrm{MgZn}_{2}$ were proposed as shown in Fig. 15,

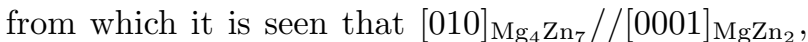

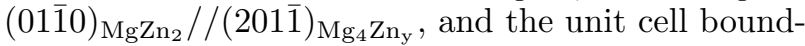
aries are shown in dark type. It is seen from Fig. 15(a) that $\mathrm{Zn}$ atoms closed to the edges of the unit cell have coordination number of 12 , and the center of icosahedral clusters is defined with their two-fold axes shown by dashed lines. Fig. 15(b) shows the $\mathrm{MgZn}_{2}$ structure, where the icosahedral in both phases shear the same orientation with the matrix. It can be seen that one of the two-fold axis parallel to the hexagonal axis of $\mathrm{Mg}$ and a second, perpendicular two-fold axis is aligned normal to the $(20 \overline{1})_{\mathrm{Mg}_{4} \mathrm{Zn}_{7}}$ and $(01 \overline{1} 0)_{\mathrm{MgZn}_{2}}$ planes.

Recent research indicated that this kind of icosahedral phase (I-phase) could also exist in the as-cast $\mathrm{Mg}-\mathrm{Li}$ alloy containing $\mathrm{Zn}$ and $\mathrm{Y}$, where it showed that both the appropriate quantity and the size of the I-phase contained in the alloy can strengthen the Mg-Li alloys ${ }^{[49]}$.

\section{Long-period Stacking Ordered Structure}

One of the important progresses in strengthening mechanism of the Mg-based alloys is discovery of a long-period stacking ordered (LPSO) structure, and it has received a considerable amount of attention as new types of strengthening phases in high strength Mg alloys. This kind of LPSO phase has been reported to be beneficial to simultaneously endow with high strength and high ductility. At the beginning of the 21 century, Kawamura et al. ${ }^{[61]}$ have published a series of papers, and reported that the yield strength and elongation of a $\mathrm{Mg}$ alloy prepared by warm extrusion of atomized powders at $573 \mathrm{~K}$ achieved $610 \mathrm{MPa}$ and $6 \%$, respectively, which are 2.5 and 5 times higher than those of conventional highstrength type Mg-based alloy, and their subsequent work suggested that the excellent mechanical properties of these alloys are ascribed to the precipitationstrengthening of a novel structure so called LPSO, except for nano-grains ${ }^{[62-65]}$. Since then, these amazing findings trigger great enthusiasm in the researches of

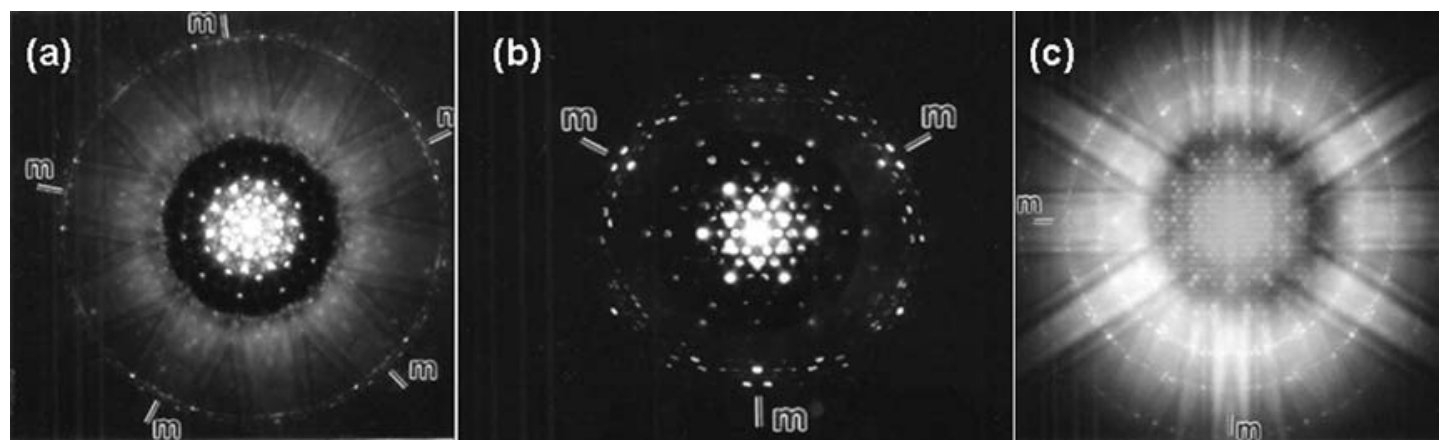

Fig. 13 Microdiffraction patterns with 5-fold (a), 3-fold (b) and 2-fold (c) symmetry axes, showing both the zeroth-order and the first-order Laue zones taken from an icosahedral quasicrystal phase in a $\mathrm{Mg}-\mathrm{Zn}-\mathrm{Al}$ cast alloy ${ }^{[43]}$ 


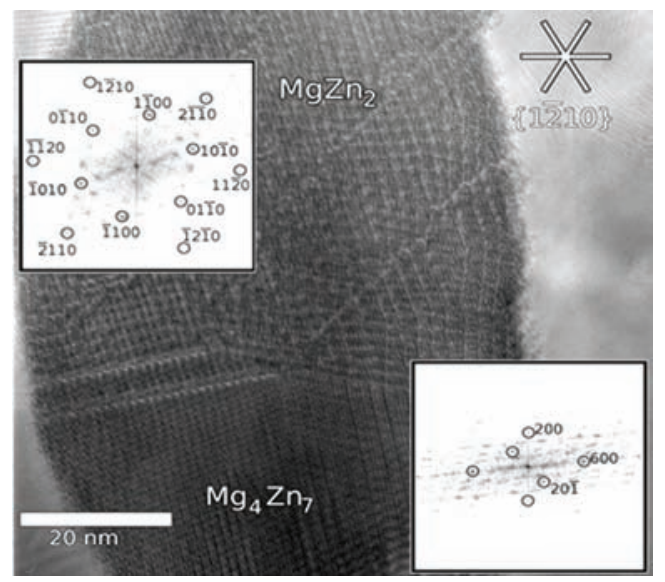

Fig. 14 Icosahedral phases formed on the twin boundary of hexagonal $\mathrm{MgZn}_{2}$ and monoclinic $\mathrm{Mg}_{4} \mathrm{Zn}_{7}$ phases in an as-cast Mg-Zn-Y alloy subjected to be deformed in compression ${ }^{[48]}$

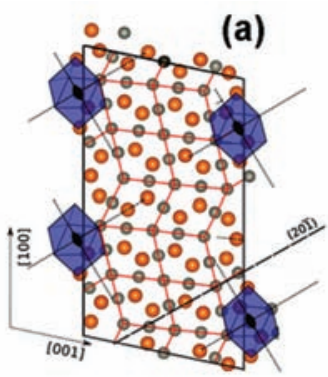

(b)

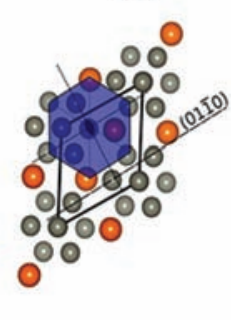

Fig. 15 The structural models of $\mathrm{Mg}_{4} \mathrm{Zn}_{7}$ (a) and $\mathrm{MgZn}_{2}$ (b) containing icosahedral ${ }^{[48]}$

LPSO until now. It should be noticed that however, the earliest observation with respect to the LPSO structure in the Mg-based alloys was made by Luo et al. $(1994,2000)^{[66,67]}$. They reported that there was X-phase in the Mg-Zn-Zr-RE cast alloys, which had an 18R modulated structure ${ }^{[67]}$, and further works by X-ray diffraction and high- resolution microscopy observation made them propose that this kind of $\mathrm{X}$-phase has an $18 \mathrm{R}$ modulated structure with a period of $4.68 \mathrm{~nm}$ with a stacking sequence of $\mathrm{ABABCACACABCBCBCABA}{ }^{[67]}$ as shown in Fig. 16, which reveals the orientation relationship between the X-phase and $\alpha$-Mg (Fig. 16(a)), and HREM image (Fig. 16(b)) shows the stacking sequence of the atoms consisting of one positive and one negative, followed by one positive and three negative stacking (Fig. 16(c)). It is evident from the observation and analysis that the $\mathrm{X}$-phase mentioned in Luo's reports is a long-period stacking ordered structure with 18R-type, and their pioneering works were verified by subsequent works in different $\mathrm{Mg}$-alloy systems $^{[61-65,68-71]}$.

In recent years, a great number of investigations regard to LPSO structures have been carried out on the $\mathrm{Mg}-\mathrm{Zn}-\mathrm{RE}(\mathrm{RE}=\mathrm{Y}$, La, Ce, Pr, Sm, Nd, Dy, Ho, Er, Gd and Tm) alloys. There are different kind of types LPSO structures, including $6 \mathrm{H}^{[62,64]}$, $10 \mathrm{H}^{[63]}, 14 \mathrm{H}^{[68]}, 18 \mathrm{R}^{[68]}$ and $24 \mathrm{R}^{[63]}$, in these kinds of alloy systems produced by different methods such as rapidly solidified, powder metallurgy ${ }^{[62,63]}$, meltspun $^{[69]}$, Cu-mold casting and induction melting ${ }^{[64]}$ and conventional casting ${ }^{[0]}$ as listed in Table 1.

Fig. 17 is the many beam bright-field (Fig. 17(a)) and atomic-resolution high angle annular dark field scanning (HAADF-STEM) (Fig. 17(b)) images taken from a fine-lamellar grain in $\mathrm{Mg}_{97} \mathrm{Zn}_{1} \mathrm{Y}_{2}$ alloy produced by $\mathrm{Cu}$-mold casting and induction melting, showing the microstructure of LPSO with $6 \mathrm{H}$ stacking sequence of $\mathrm{ABCBCB}^{[62]}$, which is formed by introduction of a faulting on every six close-packed planes of the $2 \mathrm{H}$ (hcp)- $\mathrm{Mg}$ crystal shown in Fig. 17(b) and Fig. 18. Further analysis by EDS reveals that the segregation of $\mathrm{Zn}$ and $\mathrm{Y}$ atoms on both $A$ and $B^{\prime}$ planes corresponding to the brightest Z-contrast lines leads to the break of the periodicity of $2 \mathrm{H}-\mathrm{Mg}$ long period lattice, displaying a simple chemical order in terms of every $A$ and $B^{\prime}$ layers.
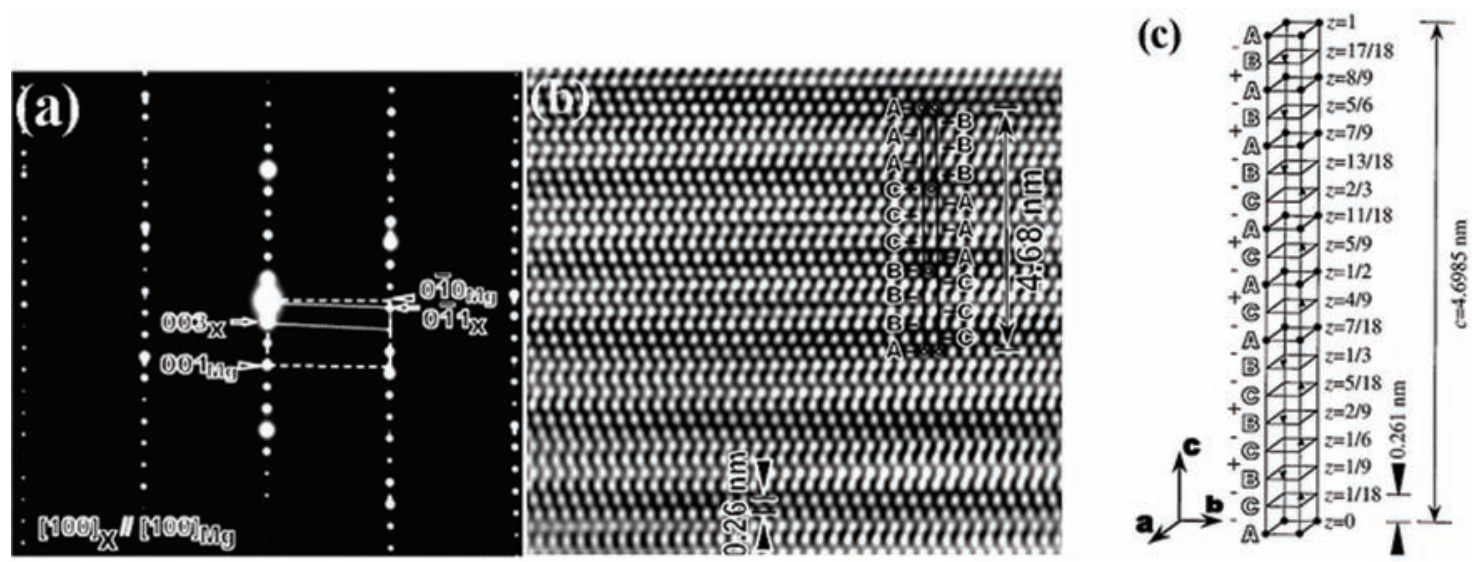

Fig. 16 SEDP (a), HREM image (b) of X-phase projected along the [100] orientation and a unit cell of the X-phase stacked by three A, B, and C layers (c) in Mg-Zn-Zr-Y cast alloy ${ }^{[67]}$ 
Table 1 LPSO structures produced by different methods in different alloy systems

\begin{tabular}{|c|c|c|c|c|}
\hline Condition & Composition & Type & State & Ref. \\
\hline & $\mathrm{Mg}_{97} \mathrm{Zn}_{1} \mathrm{Y}_{2}$ & $6 \mathrm{H}$ & Extruded at $573 \mathrm{~K}$ & {$[62]$} \\
\hline $\mathrm{RS} / \mathrm{PM}$ & $\mathrm{Mg}_{97} \mathrm{Zn}_{1} \mathrm{Y}_{2}$ & $6 \mathrm{H}$ & $\begin{array}{c}\text { At annealed at } 573 \mathrm{~K} \text { and no } 6 \mathrm{H} \\
\text { phase in initial microstructure }\end{array}$ & {$[82]$} \\
\hline \multirow{10}{*}{ Melt-spun } & $\mathrm{Mg}_{97} \mathrm{Zn}_{1} \mathrm{Y}_{2}$ & $6 \mathrm{H}$ & Extruded at $573 \mathrm{~K}$ & {$[73]$} \\
\hline & $\mathrm{Mg}_{97} \mathrm{Zn}_{1} \mathrm{Y}_{2}$ & $6 \mathrm{H}$ & Extruded at $573 \mathrm{~K}$ & {$[74]$} \\
\hline & $\mathrm{Mg}_{97} \mathrm{Zn}_{1} \mathrm{Y}_{2}$ & $18 \mathrm{R}+14 \mathrm{H}+10 \mathrm{H}+24 \mathrm{R}$ & In annealed at $573 \mathrm{~K}$ & [63] \\
\hline & $\mathrm{Mg}_{98} \mathrm{Cu}_{1} \mathrm{Y}_{1}$ & $14 \mathrm{H}$ & In melt-quenched & {$[75]$} \\
\hline & $\mathrm{Mg}_{97} \mathrm{Y}_{2} \mathrm{Zn}_{1}$ & $14 \mathrm{H} 6 \mathrm{H}$ & $\begin{array}{l}\text { (As-spun state), } \\
\text { (in annealed state) }\end{array}$ & \\
\hline & $\mathrm{Mg}_{97} \mathrm{Gd}_{2} \mathrm{Zn}_{1} \mathrm{Mg}_{97} \mathrm{Gd}_{2} \mathrm{Zn}_{1}$ & $6 \mathrm{H}$ & $\begin{array}{l}\text { (No LPSO in as-spun state) } \\
\text { (in annealed state) }\end{array}$ & {$[69]$} \\
\hline & $\mathrm{Mg}_{97} \mathrm{Sm}_{2} \mathrm{Zn}_{1} \mathrm{Mg}_{97} \mathrm{Sm}_{2} \mathrm{Zn}_{1}$ & $6 \mathrm{H}$ & $\begin{array}{l}\text { (No LPSO in as-spun state) } \\
\text { (in the annealed state) }\end{array}$ & \\
\hline & $\mathrm{Mg}_{97} \mathrm{Ce}_{2} \mathrm{Zn}_{1}$ & & $\begin{array}{l}\text { (No LPSO in the as-spun } \\
\text { and annealed states) }\end{array}$ & \\
\hline & $\mathrm{Mg}_{97} \mathrm{La}_{2} \mathrm{Zn}_{1}$ & & $\begin{array}{l}\text { (No LPSO in the as-spun } \\
\text { and annealed states) }\end{array}$ & \\
\hline & $\mathrm{Mg}_{97} \mathrm{Zn}_{1} \mathrm{Gd}_{2}$ & $14 \mathrm{H}$ & Annealed at $673 \mathrm{~K}$ & {$[71]$} \\
\hline \multirow{5}{*}{ Conventional cast } & $\mathrm{Mg}_{97} \mathrm{Y}_{2} \mathrm{Cu}_{1}$ & $18 \mathrm{R}$ & Hot-extruded & {$[74]$} \\
\hline & $\mathrm{Mg}_{96} \mathrm{Gd}_{1.2} \mathrm{Y}_{0.3-1} \mathrm{Zr}_{0.2}$ & $14 \mathrm{H}$ & Solution-treatment at $773 \mathrm{~K}$ & {$[76]$} \\
\hline & $\mathrm{Mg}_{88} \mathrm{Y}_{8} \mathrm{Zn}_{4}$ & $6 \mathrm{H}$ & In as-cast & {$[70]$} \\
\hline & $\mathrm{Mg}_{97} \mathrm{Zn}_{1} \mathrm{RE}_{2}(\mathrm{RE}=\mathrm{Y}, \mathrm{Dy}, \mathrm{Er}, \mathrm{Ho}, \mathrm{Tm})$ & $14 \mathrm{H}$ & During solidification & {$[77]$} \\
\hline & $\mathrm{Mg}_{97} \mathrm{Zn}_{1} \mathrm{RE}_{2}(\mathrm{RE}=\mathrm{Gd}, \mathrm{Tb})$ & $14 \mathrm{H}$ & Soaked at $773 \mathrm{~K}$ & {$[77]$} \\
\hline \multirow[t]{3}{*}{ Induction melting } & $\mathrm{Mg}_{96.5} \mathrm{Zn}_{1} \mathrm{Gd}_{2.5}$ & $14 \mathrm{H}$ & $\begin{array}{c}\text { Aging at } 623 \mathrm{~K}+\text { heat } \\
\text { treatment at } 773 \mathrm{~K}\end{array}$ & {$[78]$} \\
\hline & $\mathrm{Mg}_{89.4} \mathrm{Y}_{8} \mathrm{Zn}_{2} \mathrm{Zr}_{0.6}$ & $18 \mathrm{R}$ & Heat treated at $500{ }^{\circ} \mathrm{C} \rightarrow 14 \mathrm{H}^{*}$ & [79] \\
\hline & $\mathrm{Mg}_{91.16} \mathrm{Zn}_{1.2} \mathrm{Zr}_{0.48} \mathrm{Y}_{7.2}$ & $18 \mathrm{R}$ & As-cast & {$[66-67]$} \\
\hline
\end{tabular}
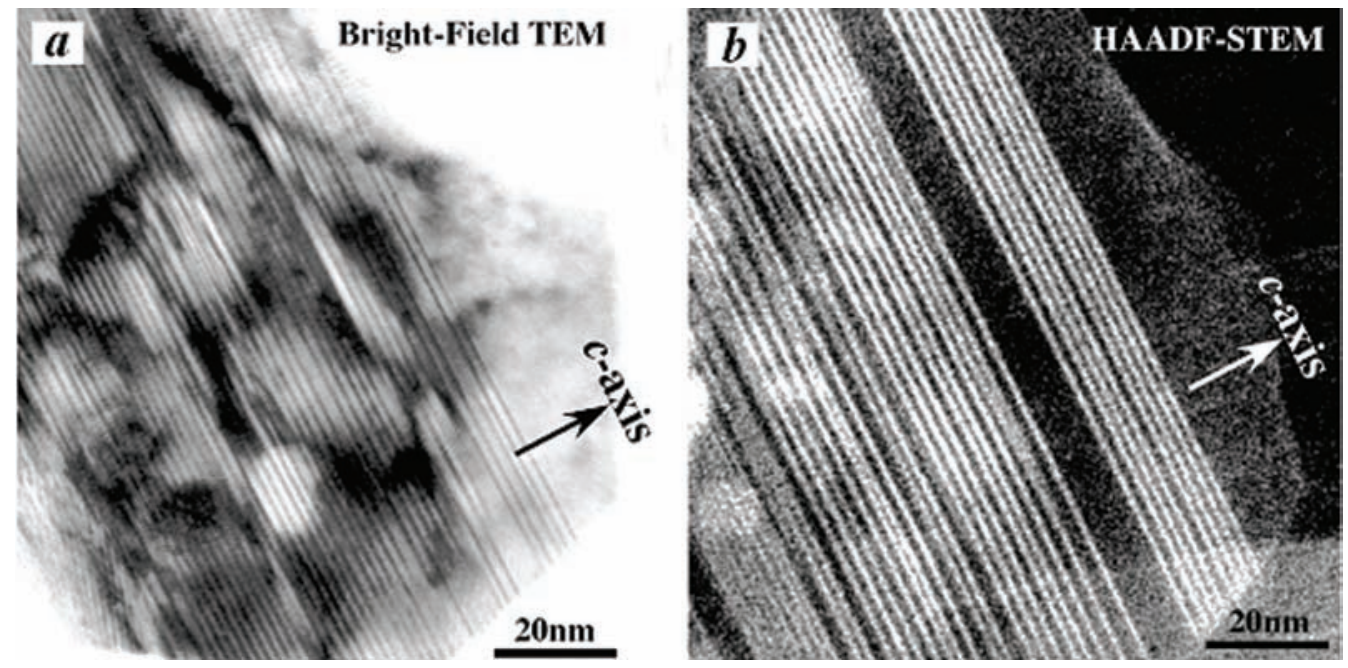

Fig. 17 Many beam bright field (a) and atomic-resolution high angle annular dark field (b) scanning TEM (HAADF-STEM) images of LPSO taken from $\mathrm{Mg}_{97} \mathrm{Zn}_{1} \mathrm{Y}_{2}$ alloy. Z-contrasts appear as bright lines in Fig. 17 (b), showing the lamellar distribution of $\mathrm{Zn}$ and $\mathrm{Y}$ atoms ${ }^{[62]}$

According to these results, Abe et al. ${ }^{[62]}$ proposed an atomic model shown in Fig. 19. 6H-type LPSO with ABCBCB stacking sequence (Fig. 19(b)) is formed by introduction of stacking faults on every six close-packed planes of $2 \mathrm{H}-\mathrm{Mg}$ crystal (Fig. 19(a)), and the segregation of solute atoms of $\mathrm{Zn}$ and $\mathrm{Y}$ around these fault layers (Fig. 19(c)). Z-contrast imaging and sub-nanometer probe analysis reveal $A$ and $B^{\prime}$-layers are segregated by both $\mathrm{Zn}$ and $\mathrm{Y}$ atoms. Because $A$ - and $B^{\prime}$ layers are enriched by some large atoms $\mathrm{Y}$, so the crystal lattice of $6 \mathrm{H}$-type LPSO Mg$(\mathrm{Zn}, \mathrm{Y})$ structure is distorted, as it is described by a monoclinic lattice with $\beta=88^{\circ}, a=0.56 \mathrm{~nm}, b=0.32$ $\mathrm{nm}$, and $c=1.56 \mathrm{~nm}$ in Fig. 19(c). 

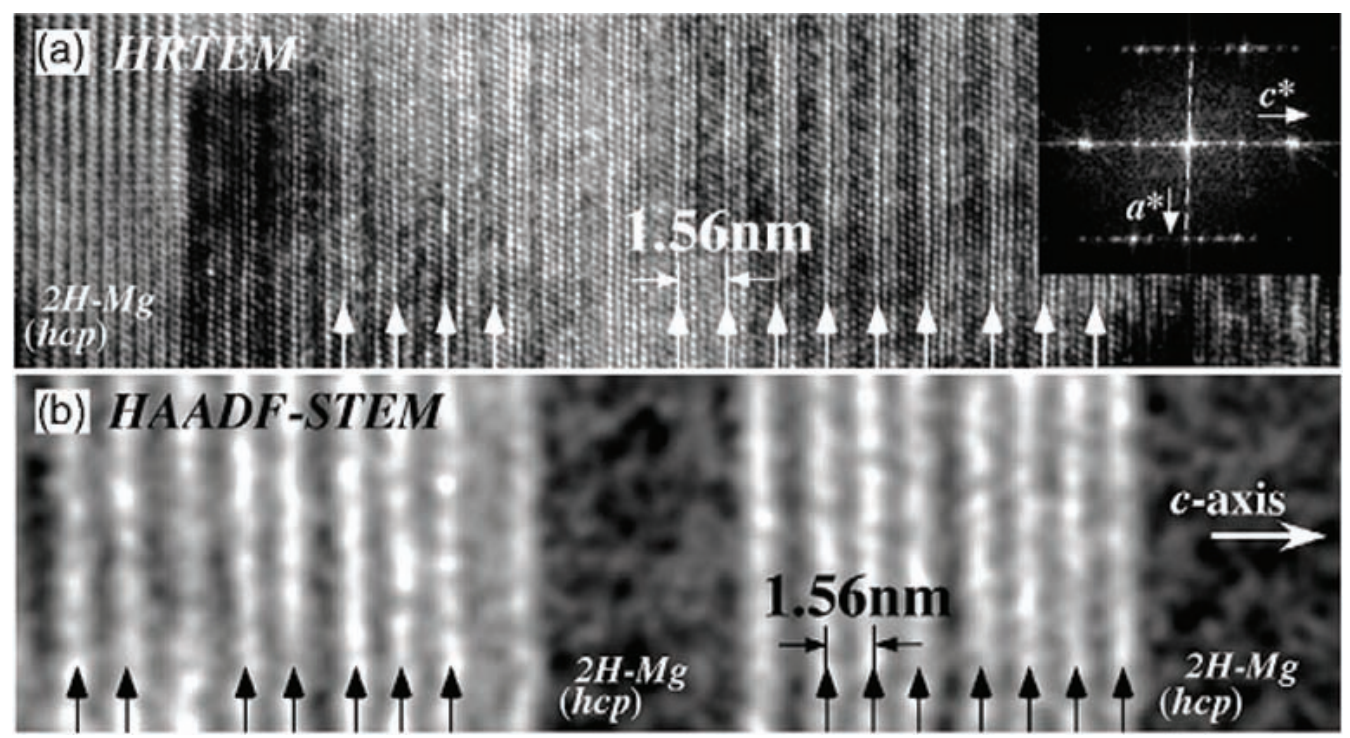

Fig. $18 \operatorname{HRTEM}(\mathrm{a})$ and HAADF-STEM (b) images showing the LPSO ordered structure. The periodic contrasts with an interval of six close-packed planes corresponding to a distance of $1.56 \mathrm{~nm}$ observed in $\mathrm{Mg}-\mathrm{Zn}-\mathrm{Y}$ alloy. The lamellar Z-contrasts with the same interval of $1.56 \mathrm{~nm}$ at some planes (b), showing a chemical order of the $6 \mathrm{H}$-type structure ${ }^{[62]}$

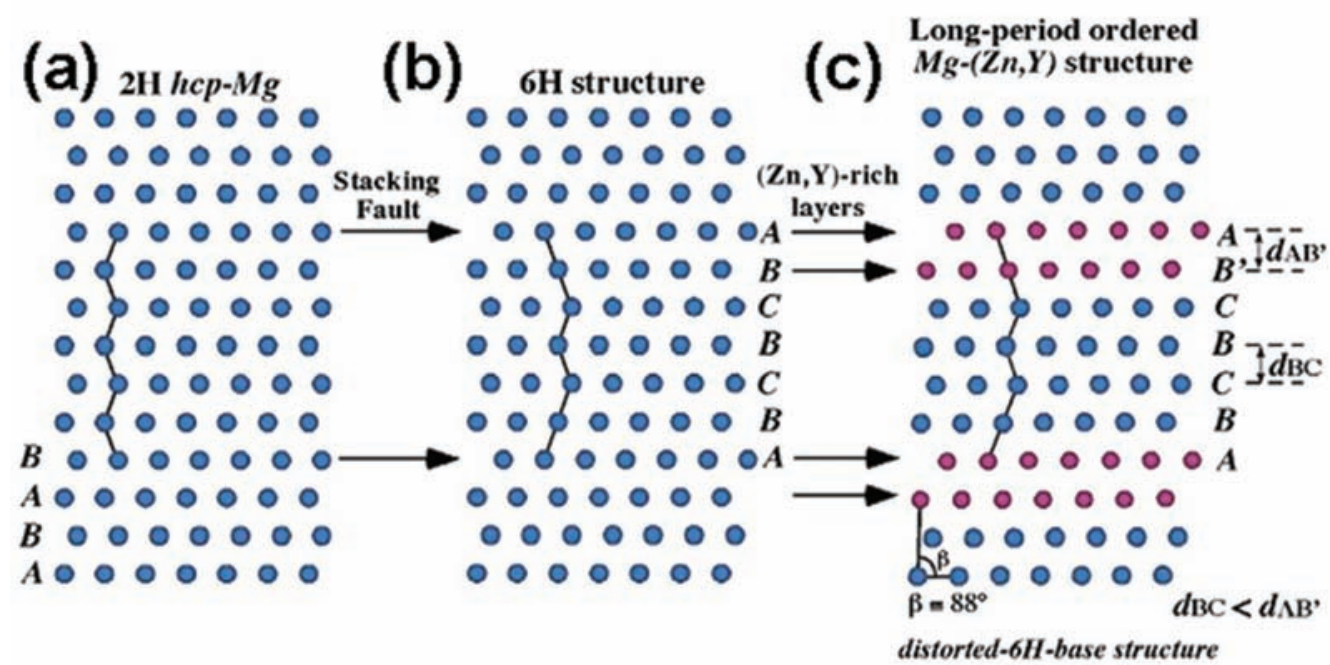

Fig. 19 An atomic structure model of 6H-type with ABCBCB sequence, showing the relationship among the hcp$\mathrm{Mg}$ (2H-type) (a), 6H type (b) and LPSO model (c) formed in $\mathrm{Mg}(\mathrm{Zn}, \mathrm{Y})$ alloy ${ }^{[62]}$

\subsection{LPSO formation independence of the heating temperature}

Yamasaki et al. ${ }^{[78]}$ reported that the precipitation behavior of the Mg-Zn-Gd casting alloy is different with variation of the treat temperature, and the precipitation sequence of the precipitates is changed with variation of the treat temperature as follows:

$$
\begin{gathered}
\sim 573 \mathrm{~K}: \alpha-\operatorname{Mg}(\mathrm{SSSS}) \rightarrow \beta^{\prime} \rightarrow \beta_{1} \rightarrow \beta \\
\alpha-\mathrm{Mg}(\mathrm{SSSS}) \rightarrow \mathrm{SF} \\
\sim 673 \mathrm{~K}: \quad \alpha-\mathrm{Mg}(\mathrm{SSSS}) \rightarrow \mathrm{SF} \rightarrow \mathrm{LPSO}
\end{gathered}
$$

This indicates that at a low temperature ( $\sim 573 \mathrm{~K})$, the $\beta$ ' precipitates during aging and over- aging will lead to the precipitation of a thermally stable $\beta$ via the $\beta_{1}$. It reveals that there is short of LPSO structure during precipitation process around this temperature. However, at a high temperature $(\sim 673 \mathrm{~K})$, the LPSO occurs mainly around the stacking faults (SF) which are introduced by the decrease in stacking fault energy. This result further verified the earlier observation of Nishida et al. ${ }^{[72]}$ found that $6 \mathrm{H}$ LPSO phase occurred in the RS ribbon annealed up to $773 \mathrm{~K}$, but not occurred in RS/PM Mg${ }_{97} \mathrm{Zn}_{1} \mathrm{Y}_{2}$ alloy when annealed at $823 \mathrm{~K}$.

\subsection{Effect of alloying additions on the LPSO forma- tion}

It should be stressed that the studies of LPSO 
structures in Mg-alloys are mainly focused on $\mathrm{Mg}-\mathrm{Zn}-$ RE system, where RE represents Y, La, Ce, Pr, Sm, Nd, Dy, Ho, Er, Gd, Tb, Tm or Yb. Kawamura et al. ${ }^{[71,72]}$ classified the LPSO in Mg-Zn-RE alloy systems into two types. One is the $\mathrm{Mg}-\mathrm{Zn}$ alloys containing rare-earth elements of $\mathrm{Y}, \mathrm{Dy}, \mathrm{Ho}$, and Er, in which LPSO with $18 \mathrm{R}$ can transform into $14 \mathrm{H}$ structure during high temperature treatment at $773 \mathrm{~K}$ for $5 \mathrm{~h}$. The others are the Mg-Zn alloys containing Gd, $\mathrm{Tb}$, and Tm, in which there is no LPSO in the as-cast state, but it may precipitate from the $\alpha$-Mg (SSSS) during annealing at high temperature.

Based on the description mentioned above, it seems that $\mathrm{Zn}$ is an indispensable solute element in the formation of the LPSO for the Mg-RE alloy systems. Inoue et al. ${ }^{[73]}$ noticed that there is no LPSO in the melt-spun alloys in ternary $\mathrm{Mg}-\mathrm{Al}-\mathrm{Y}$, and binary $\mathrm{Mg}-\mathrm{Y}$ and $\mathrm{Mg}-\mathrm{Zn}$, but the addition of $\mathrm{Zn}$ into $\mathrm{Mg}$ $\mathrm{Y}$ leads to formation of $6 \mathrm{H}$ LPSO phase. The same result was also obtained by Gao et al. ${ }^{[79]}$. They attributed this to the absence of the plane faults in the alloys. Yamada et al. ${ }^{[76]}$ also found that there was a definite range of $\mathrm{Zn}$ addition for the formation of the LPSO in the Mg-Gd-Y-Zn-Zr alloys, and it does not occur when the content of $\mathrm{Zn}$ in the alloy is too low $(<0.3$ wt. $\%)$ or high $(>1.0$ wt. $\%)$.

Some researches indicate that the precipitation reactions in the alloys based on the Mg-Y-Nd, Mg-Dy$\mathrm{Nd}$ and $\mathrm{Mg}-\mathrm{Gd}-\mathrm{Nd}$ systems showed three- or fourstage precipitation sequence as follows:

$$
\begin{gathered}
\alpha-\operatorname{Mg}(\mathrm{SSSS}) \rightarrow \beta^{\prime \prime} \rightarrow \beta^{\prime}(\text { Ref. [80]) } \\
\alpha-\operatorname{Mg}(\mathrm{SSSS}) \rightarrow \beta^{\prime \prime} \rightarrow \beta^{\prime} \rightarrow \beta_{1}(\text { Ref. [81]) }
\end{gathered}
$$

From these precipitation sequences, there is no LPSO structure in these alloy systems due to Zn-free, indicating the indispensable role of element $\mathrm{Zn}$ in formation of LPSO structure. This implies that $\mathrm{Zn}$ and $\mathrm{RE}$ are required for LPSO formation in Mg-RE alloy systems. Some exceptions however are that in some alloy systems, such as $\mathrm{Mg}-\mathrm{Y}-\mathrm{Cu}^{[70]}$ and $\mathrm{Mg}-\mathrm{Y}-$ $\mathrm{Ni}^{[68,82]}$, LPSO structures were also observed due to the atom size effect of the substitute element. It is seen that the atom size of $\mathrm{Cu}$ in $\mathrm{Mg}-\mathrm{Y}-\mathrm{Cu}$ alloy is close to that of $\mathrm{Zn}$, and the atom radium of $\mathrm{Ni}$ in $\mathrm{Mg}-\mathrm{Y}-\mathrm{Ni}$ alloy is larger than of $\mathrm{Zn}$ but is still smaller than that of $\mathrm{Y}$. It is worthy to note that the mixing enthalpies of every atom pair of Mg-RE, Zn-RE and substitute elements $\mathrm{Cu}-\mathrm{RE}$ and $\mathrm{Ni}-\mathrm{RE}$ are all negative, leading to the formation of LPSO structures ${ }^{[68,73,77]}$.

Matsuda et al. ${ }^{[62,83,84]}$ reported that there were five kinds of LPSO structures, i.e. 18R, $14 \mathrm{H}, 10 \mathrm{H}, 24 \mathrm{R}$ and $6 \mathrm{H}$ in $\mathrm{RS}-\mathrm{Mg}_{97} \mathrm{Zn}_{1} \mathrm{Y}_{2}$ alloy annealed at $573 \mathrm{~K}$. The difference of the stacking sequence in these LPSO structures is proposed to be difference of the chemical compositions in each structure. Most observations have showed that the LPSO phase nucleates preferentially at the grain boundaries where the elements such $\mathrm{Y}$ and $\mathrm{Zn}$ and so on, segregated during

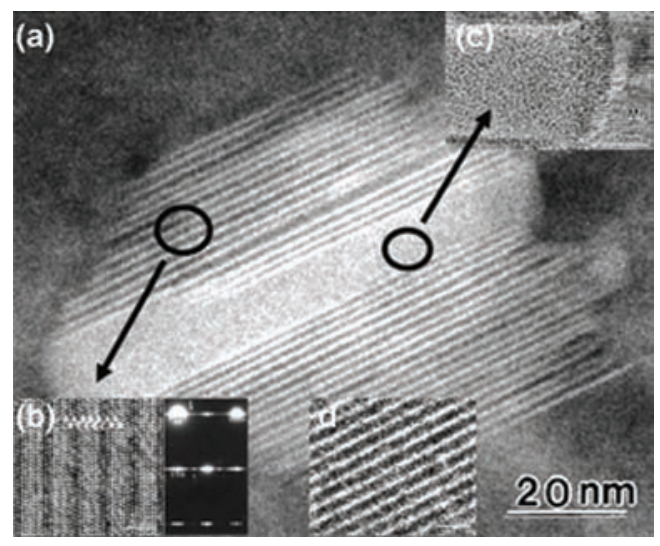

Fig. 20 HAADF-STEM image showing the formation process of $14 \mathrm{H}$ LPSO in $\mathrm{Mg}_{98} \mathrm{Cu}_{1} \mathrm{Y}_{1}$ alloy ${ }^{[75]}$

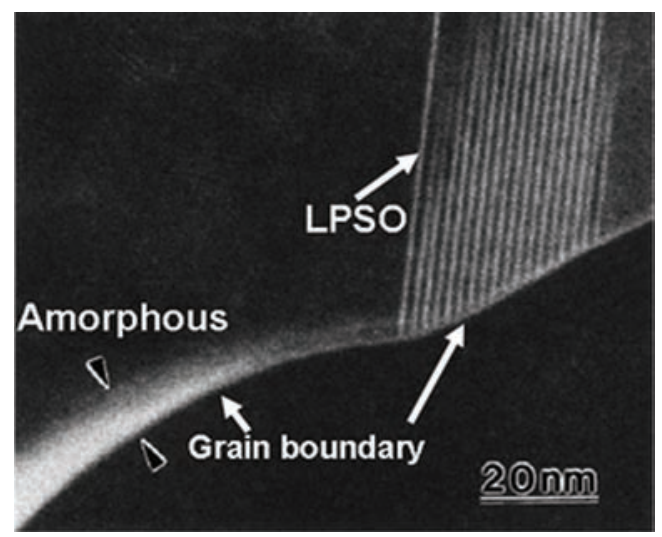

Fig. 21 Distribution of the amorphous layer and LPSO structures along the grain boundary ${ }^{[75]}$

solidification, and then grows into the grain interior along the basal plane. In other words, LPSO structure formation is accompanied by a diffusion transformation of the solute elements. That is to say, it is not only structurally the stacking ordered but also chemically ordered structure. These indicate that the LPSO structure formation is closely related to both the heat treatment and solute elements as listed in Table 1. According to the observations and analyses mentioned above, it is evident that the LPSO formation is related to the solute atom size and the mixing enthalpy of the alloy system.

Matsuura et al. ${ }^{[75]}$ proposed the formation mechanism of LPSO in the $\mathrm{Mg}-\mathrm{Cu}-\mathrm{Y}$ alloy as shown in Fig. 20. It can be seen that there are 14H LPSO (Fig. 20(b)), and amorphous layer (Fig. 20(c)). The solute atoms $\mathrm{Cu}$ and $\mathrm{Y}$ are enriched at two atom planes (Fig. 20(d)) across stacking faults in the stacking sequence of the $14 \mathrm{H}$ LPSO structure, where the arrows indicate the stacking faults. Fig. 21 shows an amorphous layer along the grain boundary and the LPSO crystal growing from the boundary into the Mgmatrix by consuming the amorphous layer and the migration of $\mathrm{Y}$ atoms in the Mg-matrix, which was confirmed by the observation of Gao et al. ${ }^{[79]}$. They found 


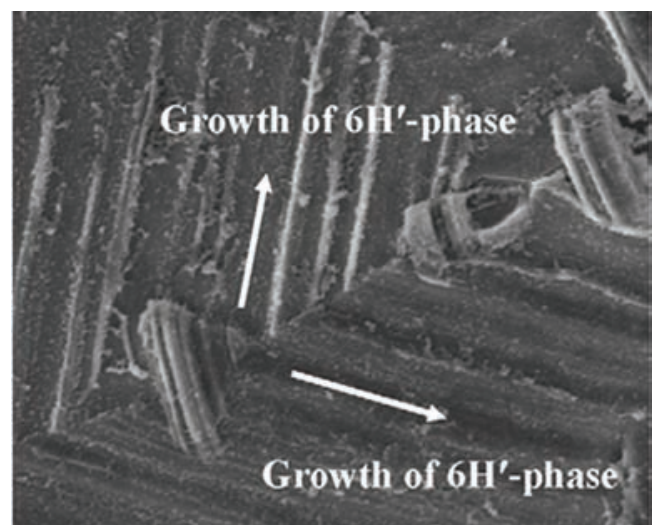

Fig. 22 LPSO phase growth from the grain boundaries into the grain interior ${ }^{[79]}$

the evidence of the growth of LPSO phases from the grain boundary into Mg-matrix, as shown in Fig. 22.

Matsuura et al. ${ }^{[75]}$ pointed out that the solubilities of $\mathrm{Cu}$ and $\mathrm{Y}$ in $\mathrm{Mg}$ alloy are low, and they are enriched in the amorphous region, and then can migrate toward the grain boundary leading to the formation of LPSO structure in this kind of alloy.

\section{Further Research Proposed}

In this review, we summarize the formation and microstructures of the precipitates mainly including G.P. Zones, quasicrystals and long-period stacking ordered phases as a hot topic at present, produced in a numbers of $\mathrm{Mg}$-TM-RE alloy systems, where $\mathrm{TM}=\mathrm{Al}$, $\mathrm{Zn}, \mathrm{Zr}$ and $\mathrm{RE}=\mathrm{Y}, \mathrm{Gd}, \mathrm{Hd}$, Ce, and it does not involve the other current precipitation phases produced in various $\mathrm{Mg}$-based alloy systems, such as $\mathrm{Mg}_{x} \mathrm{Al}_{y}$ in $\mathrm{Mg}-\mathrm{Al}$ system, $\mathrm{Mg}_{x} \mathrm{Zn}_{y}$ in $\mathrm{Mg}-\mathrm{Zn}$ system, $\mathrm{Mg}_{x} \mathrm{RE}_{y}$ in Mg-RE system (where $x$ and $y$ represent the natural numbers which are lager than zero). Although material scientists have made lots of efforts to work on the formation mechanism and microstructures of G.P. Zones, quasicrystals and long-period stacking ordered phases and got a great progress during last decade, it is still quite hard to get a systematic understanding in depth of the precipitation regularity and a number of questions still remain open, particularly about Quasicrystal phases and LPSO phases. We would like to indicate some of the areas that would be worthwhile of scientific inquiry:

(1) It is known that the addition of the elements has a pronounced effect of age-hardening response of the magnesium alloys ${ }^{[8-12]}$. For example, the addition of $\mathrm{Zn}$ into the $\mathrm{Mg}-\mathrm{Ca}$ alloy makes the G.P. zones occur, which may enhance the age-hardening response of the alloys strongly, but when the content of $\mathrm{Zn}$ in the alloy exceeds a certain amount, the age-hardening response becomes weaker ${ }^{[8]}$. It is found that the segregation of $\mathrm{Zn}$ in G.P. zone in the $\mathrm{Mg}-\mathrm{Zn}$ alloy is significant, and $\mathrm{Zn} / \mathrm{Mg}$ ratio (at.\%) may reach $1: 2$, which is much higher than that in
Mg-matrix approaching 1.9:98.1 ${ }^{[85]}$. It is also reported that G.P. zones can occur in the alloys with $\mathrm{Gd} / \mathrm{Zn}=2$ for $\mathrm{Mg}_{97} \mathrm{Gd}_{2} \mathrm{Zn}_{1}, \mathrm{Gd} / \mathrm{Zn}=1$ and 1.5 for $\mathrm{Mg}_{99} \mathrm{Gd}_{0.5} 1 \mathrm{Zn}_{0.5}$ and $\mathrm{Mg}_{97.5} \mathrm{Gd}_{1.5} \mathrm{Zn}_{1}$ by annealing at $200{ }^{\circ} \mathrm{C}$ for $100 \mathrm{~h}^{[9,10]}$. These imply that there is a certain amount of $\mathrm{Zn}$ addition to be required for an optimal strengthening effect of the alloy, and further investigations of the structure, element segregation as well as the precipitation processes of the G.P. zones at different aging temperatures for the alloys are still needed. Therefore, the researches in depth of the fine structure, composition segregation and the transformation in G.P. zones are hopeful for a better understanding of the G.P. zone formation mechanism

(2) The formation of the quasicrystals in magnesium alloys has widely been found on both systems of $\mathrm{Mg}-\mathrm{Zn}-\mathrm{RE}(\mathrm{RE}=\mathrm{Y}, \mathrm{Gd}$ and $\mathrm{Nd})$ rare-earth containing and of $\mathrm{Mg}-\mathrm{Al}-X(X=\mathrm{Zn}$ and $\mathrm{Cu})$. The quasicrystal production is related to the $\mathrm{Zn} / \mathrm{RE}$ weight ratio in the alloy, and it is found that when the ratio is between 6 and $10^{[86]}$, the quasicrystal phase (I-phase) occurs, meaning that the regulation of the $\mathrm{Zn} / \mathrm{RE}$ ratio is required for quasicrystal formation, but the universal and applicable $\mathrm{Zn} / \mathrm{RE}$ ratio and solute element effect of the quasicrystal phase formation in this kind of alloys is still needed to be worked further. Moreover, the quasicrystal phases have also been observed in $\mathrm{Mg}-\mathrm{Al}-X(X=\mathrm{Zn}$ and $\mathrm{Cu})$ non-rare-earth containing alloys. These imply that the factors effecting formation of the quasicrystal phases are quite complex. The systematic experimental works and theoretical analysis still have got a long way going, and the issues such as the regularity for quasicrystal formation; the quasilattice and its structural model; the phase transformation and defects in the quasicrystal, particularly, the structural relationships between the stable and one, two- and three-dimension quasicrystals; the conditions and processing for the quasicrystal growth; the growth of large-size quasicrystal monocrystal as well as large area quasicrystal multi-crystal thin film. Besides, the some important fields such as the electricity, magnetics, mechanics and optics of the quasicrystals should be paid more attentions.

Extensive researches and explorations of the quasicrystal have not only developed a number of the aluminum alloys with high-strength, but also found some novel ultra-light Al-Li alloys making the strength of the alloy containing the icosahedral phase reach 250 $\mathrm{MPa}$, showing a new prospect for the design and development of the ultra-light and high-strength $\mathrm{Mg}$ alloys $^{[49]}$.

(3) A number of factors influence its formation, growth and microstructure of the LPSO phase, including production processing ${ }^{[67]}$, heat treatment ${ }^{[72]}$ and alloying additions ${ }^{[80]}$, etc.. Thus it is inartificial to query what are the main factors influencing its formation and growth. From the alloying additions, it has already been noted that a certain amount of $\mathrm{Zn}$ and $\mathrm{Y}$, particularly $\mathrm{Zn}$ is essential to form LPSO struc- 
ture in the Mg-Zn-RE alloy systems. In other words, it seems to have a critical amount of $\mathrm{Zn}$ and $\mathrm{Y}^{[73,76]}$ and their ratio, therefore, some systematic works are necessary on these problems.

It is known that the mechanical performance of $\mathrm{Mg}$ alloys containing LPSO structures strongly depends on the deformation behaviors, such as dislocation slip, twinning and kinking ${ }^{[87]}$. However, there has been relatively little work on the investigation of the deformation mechanism to be reported so far. The relationship among the deformation mechanisms is closely related to the size, volume friction and distribution of the LPSO structures. Therefore the systematic research of the interaction of dislocations, twinning and kinking is of interest and very important for a better understanding of the mechanical behavior for the LPSO containing Mg alloy. Moreover, the issues such as transformation of LPSO structures subjected to high temperature deformation, and corrosion behavior are also needed to be studied in the later investigations.

\section{Acknowledgements}

This work was supported by National Natural Science Fundation of China (Nos. 51171192 and 51271183), National Basic Research Program of China (No. 2013CB632205), and Innovation Fund of Institute of Metal Research (IMR), Chinese Academy of Sciences (CAS).

\section{REFERENCES}

[1] A. Guinier, Nature 142 (1938) 569.

[2] G.P. Preston, Nature 142 (1938) 570.

[3 ] A. Guinier, J. Phys. Radium 3 (1942) 124.

[4] A. Guinier, Comptes Rendus Hebdomadaires Des Seances De L Academie Des Sciences 231 (1950) 655.

[5 ] T.J. Konno, K. Hiraga and M. Kawasaki, Scr. Mater. 44 (2001) 2303.

[6 ] J. Buha, Mater. Sci. Eng. A 492 (2008) 11.

[7] C.J. Bettles, M.A. Gibson and K. Venkatesan, Scr. Mater. 51 (2004) 193.

[8 ] J.C. Oh, T. Ohkubo and T. Hono, Scr. Mater. 53 (2005) 675.

[9 ] K. Saito, M. Nishijima and K. Hiraga, Mater. Trans. 51 (2010) 1712.

[10] K.Saito, M.Nishijima and K.Hiraga, J. Alloys Compd. 509 (2011) 2031.

[11] D.H. Ping, K. Hono and J.F. Nie, Scr. Mater. 48 (2003) 1017.

[12] M. Nishijima, K. Hiraga, M. Yamasaki and Y. Kawamura, Mater.Trans. 49 (2008) 227.

[13] D. Shechtman, I. Blech, D. Gratias and J.W. Cahn, Phys. Rev. Lett. 53 (1984) 1951.

[14] Z. Zhang, H.Q. Ye and K.H. Kuo, Philos. Mag. 52 (1985) 149.

[15] Z. Zhang, H.Q. Ye and K.H. Kuo, Philos. Mag. A 59 (1985) 49.

[16] N. Wang, H. Chen and K.H. Kuo, Phys. Rev. Lett. 59 (1987) 1010.

[17] K.H. Kuo, Quasicrystal 35 (1990) 1691.
[18] L. Pauling, Phys. Rev. Lett. 58 (1987) 365.

[19] L. Pauling, Nature 317 (1985) 512.

[20] L. Pauling and L. Pauling, PNAS, 86 (1989) 9637.

[21] D. Shechtman, Phys. Scr. T 23 (1988) 49.

[22] D. Shechtman, J. Phys. Colloques 47 (1986) 3

[23] D. Shechtman, J. Met. 37 (1985) 62.

[24] T. Rajasekharan, D. Akhtar, R. Gopalan and K. Muraleedharan, Nature 322 (1986) 528.

[25] C.L. Henley, J. Non-Cryst. Solids 75 (1985) 91.

[26] K. Rao, N. Karpe, R. Malmhall, H. Astrum and H. Chen, MRS Proc. 58 (1985) 229.

[27] L.M. Angers, L.D. Marks and J.R. Weertman, MRS Proc. 58 (1985) 255.

[28] N.K. Mukhopadhyay, G.N. Subbanna, S. Ranganathan and K. Chattopadhyay, Scr. Mater. 20 (1986) 525.

[29] K.M. Knowles and W.M. Stobbs, Nature 323 (1986) 313.

[30] J.B. Sokoloff, Phys. Rev. Lett. 57 (1986) 2223.

[31] E. Voisin and A. Pasturel, Philos. Mag. Lett. 55 (1987) 123.

[32] D.V. Baxter, R.Richter and J.O. Strom-Olsen, Phys. Rev. B 35 (1987) 4819.

[33] S. Baranidharan, E.S.R. Gopal and G. Parthasarathy, Scr. Mater. 21 (1987) 1623.

[34] P.A. Heiney, P.A. Bancel and P.M. Horn, Science 238 (1987) 660.

[35] G. Lapasset and A. Loiseau, J. De Phys. 48 (1987) 489.

[36] D. Shechtman, in: C.H. Janot and J.M. Dubois (Eds.), Proceedings of the I.L.L./CODEST Workshop: Quasicrystalline Materials, Grenoble, France, 21-25 March, 1988.

[37] N. Koshikawa, S. Yoda and K.E dagawa, Jpn. J. Appl. Phys. 40 (2001) 628.

[38] T. Shibuya, K. Kimura and S.Takeuchi, Jpn. J. Appl. Phys. 27 (1988) 1577.

[39] G. Sastry and P. Ramachandrarao, J. Mater. Res. 1 (1986) 247.

[40] N. Koshikawa, S. Sakamoto and T. Edagawa, Jpn. J. Appl. Phys. 31 (1992) 966.

[41] U. Mizutani, T. Takeuchi and T. Fukunaga, Mater. Trans. JIM (Jpn.) 34 (1993) 102.

[42] E. Ivanov, B. Bokhonov and I. Konstanchuk, J. Mater. Sci. 26 (1991) 1409.

[43] L. Bourgeois, C.L. Mendis, B.C. Muddle and J.F. Nie, Philos. Mag. Lett. 81 (2001) 709.

[44] L. Bourgeois, B.C. Muddle and J.F. Nie, Acta Mater. 49 (2001) 2701.

[45] Z.P. Luo, S.Q. Zhang, Y.L. Tang and D.H. Zhao, Scr. Mater. 28 (1993) 513.

[46] D.K. Xu, L. Liu, Y.B. Xu and E.H. Han, Acta. Mater. 56 (2008) 985.

[47] J.Y. Lee, H.K. Lim, D.H. Kim, W.T. Kim and D.H. Kim, Mater. Sci. Eng. A 449-451 (2007) 987.

[48] J.M. Rosalie, H. Somekawa, A. Singh and T. Mukai, Philos. Mag. 91 (2011) 2634.

[49] D.K.Xu, L.Liu, Y.B. Xu and E.H. Han, Scr. Mater. 57 (2007) 285.

[50] Z.P. Luo, S.Q. Zhang, Y.L. Tang and D.H. Zhao, Scr. Mater. 28 (1993) 513

[51] A. Tsai, A. Niikura, A. Inoue, T. Masumoto, Y. Nishida, K. Tsuda and M. Tanaka, Philos. Mag. Lett. 70 (1994) 169 
[52] T.J. Sato, E. Abe and A.P. Tsai, Mater. Sci. Eng. A 304-306 (2001) 867.

[53] A. Tsai, A. Niikura, A. Inoue and T. Masumoto, J. Mater. Res. 12 (1997) 1468.

[54] D.K. Xu, W.T. Tang, L. Liu, Y.B. Xu and E.H. Han, J. Alloys. Compd. 432 (2007) 129.

[55] D.K. Xu, L. Liu, Y.B. Xu and E.H. Han, J. Alloys. Compd. 426 (2006) 155.

[56] J.Y. Lee, D.H. Kim, H.K. Lim and D.H. Kim, Mater. Lett. 59 (2005) 3801.

[57] D.K. Xu, L. Liu, Y.B. Xu and E.H. Han, Metall. Mater. Trans. A 40 (2009) 1727.

[58] D.K. Xu and E.H. Han, Prog. Nat. Sci.: Mater. Int. 22 (2012) 364.

[59] D. Bae, S. Kim, D. Kim and W. Kim, Acta Mater. 50 (2002) 2343.

[60] S. Yi, E.S. Park, J.B. Ok, W.T. Kim and D.H. Kim, Mater. Sci. Eng. A 300 (2001) 312.

[61] Y. Kawamura, K. Hayashi, A. Inoue and T. Masumoto, Mater. Trans. 42 (2001) 1172.

[62] E. Abe, Y. Kawamura, K. Hayashi and A. Inoue, Acta Mater. 50 (2002) 3845.

[63] M. Matsuda, S. Ii, Y. Kawamura, Y. Ikuhara and M. Nishida, Mater. Sci. Eng. A 393 (2005) 269.

[64] T. Itoi, T. Seimiya, Y. Kawamura and M. Hirohashi, Scr. Mater. 51 (2004) 107.

[65] H. Akiyama and Y. Kawamura, Mater. Sci. Forum. 706-709 (2012) 1117.

[66] Z.P. Luo, S.Q. Zhang, Y.L. Tang and D.S. Zhao, J. Alloys Compd. 209 (1994) 275.

[67] Z. Luo and S. Zhang, J. Mater. Sci. Lett. 19 (2000) 813

[68] Y.M. Zhu, A.J. Moron and J.F. Nie, Acta Mater. 58 (2010) 2936.

[69] K. Amiya, T. Ohsuna and A. Inoue, Mater.Trans. 44 (2003) 2151.

[70] Y. Chino, M. Mabuchi, S. Hagiwara, H. Iwasaki, A.Yamamoto and H. Tsubakino, Scr. Mater. 51
(2004) 711.

[71] M. Yamasaki, M. Sasaki, M.Nishijima, K.Hiraga and Y.Kawamura, Acta Mater. 55 (2007) 6798.

[72] M. Nishida, Y. Kawamura and T. Yamamuro, Mater. Sci. Eng. A 375-377 (2004) 1217.

[73] A. Inoue, M. Matsushita, Y. Kawamura, K. Amira, K. Hayashi and J. Koike, Mater. Trans. 43 (2002) 580.

[74] Y. Kawamura, T. Kasahara, S. Izumi and M. Yamasaki, Scr. Mater. 55 (2006) 453.

[75] M. Matsuura, K. Konno, M. Yoshida, M. Nishijima and K. Hiraga, Mater. Trans. 47 (2006) 1264.

[76] K. Yamada, Y. Okubo, M. Shiono, H. Watanabe, S. Kamado and Y. Kojima, Mater. Trans. 47 (2006) 1068.

[77] Y. Kawamara and M. Yamasaki, Mater. Trans. 48 (2007) 2986.

[78] M. Yamasaki, T. Anan, S. Yoshimoto and Y. Kawamura, Scr. Mater. 53 (2005) 799.

[79] Y. Gao, Q. Wang, J. Gu, Y. Zhao, Y. Tong and D. Yin, J. Alloys Compd. 477 (2009) 374.

[80] P.J. Apps, H. Karimzadeh, J.F. King and G.W. Lorimer, Scr. Mater. 48 (2003) 1023.

[81] J.F. Nie and B.C. Muddle, Acta Mater. 48 (2000) 1961.

[82] T. Itoi, K. Takahashi, H. Moriyama and M. Hirohashi, Scr. Mater. 59 (2008) 1155.

[83] M. Nishida, T. Yamamuro, M. Nagano, Y. Morizono and Y. Kawamura, Mater. Sci. Forum. 419-422 (2003) 715.

[84] X.H. Shao, Z.Q. Yang and X.L. Ma, Acta Mater. 58 (2010) 4760.

[85] X.L. Wang, C.R. Li, C.P. Guo and Z.M. Du, Acta Metall. Sin. 46 (2010) 575. (in Chinese)

[86] H. Li, W.B. Du, S.B. Li and Z.H. Zhang. Mater. Des. 35 (2012) 259.

[87] X.H. Shao, Ph.D Dissertation, Institute of Metal Research, Chinese Academy of Sciences, April 2011, Shenyang, China. (in Chinese) 